\title{
Fine Particle and Toxic Metal Emissions from the Combustion of Sewage Sludge/Coal Mixtures: A Systematic Assessment.
}

\author{
Final Report
}

Period of performance: 10/1/00 - 9/30/03

By

Jost O.L. Wendt, Wayne S. Seames, Art Fernandez and Mark L. Witten

February 2, 2004

DE-F26-00NT40838

Department of Chemical and Environmental Engineering

University of Arizona

Tucson, AZ 85721 


\section{DISCLAIMER}

This report was prepared as an account of work sponsored by an agency of the United States Government. Neither the United States Government nor any agency thereof, nor any of their employees, makes any warranty, express or implied, or assumes any legal liability or responsibility for the accuracy, completeness, or usefulness of any information, apparatus, product, or process disclosed, or represents that its use would not infringe privately owned rights. Reference herein to any specific commercial product, process, or service by trade name, trademark, manufacturer, or otherwise does not necessarily constitute or imply its endorsement, recommendation, or favoring by the United States Government or any agency thereof. The views and opinions of the authors expressed herein do not necessarily state or reflect those of the United States Government or any agency thereof. 


\begin{abstract}
This research project focuses on pollutants from the combustion of mixtures of dried municipal sewage sludge (MSS) and pulverized coal. The objective was to determine potential tradeoffs between $\mathrm{CO}_{2}$ mitigation through using a $\mathrm{CO}_{2}$ neutral fuel, such as municipal sewage sludge, and the emergence of other potential problems such as the emission of toxic fly ash particles. The work led to new insight into mechanisms governing the partitioning of major and trace metals from the combustion of sewage sludge, and mixtures of coal and sewage sludge. The research also showed that the co-combustion of coal and sewage sludge emitted fine particulate matter that might potentially cause greater lung injury than that from the combustion of either coal alone or municipal sewage sludge alone. The reason appeared to be that the toxicity measured required the presence of large amounts of both zinc and sulfur in particles that were inhaled. MSS provided the zinc while coal provided the sulfur. Additional research showed that the toxic effects could most likely be engineered out of the process, through the introduction of kaolinite sorbent downstream of the combustion zone, or removing the sulfur from the fuel. These results are consequences of applying "Health Effects Engineering" to this issue. Health Effects Engineering is a new discipline arising out of this work, and is derived from using a collaboration of combustion engineers and toxicologists to mitigate the potentially bad health effects from combustion of this biomass fuel.
\end{abstract}




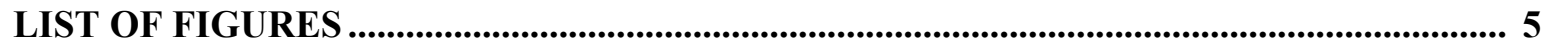

LIST OF TABLES .................................................................................................................................. 6

$1.0 \quad$ INTRODUCTION ........................................................................................................................ 7

2.0 EXECUTIVE SUMMARY .................................................................................................... 10

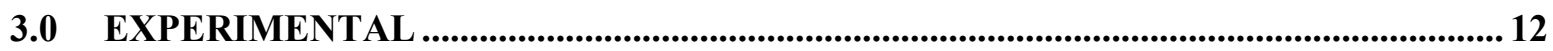

3.1 Experimental facilities for trace metal partitioning studies .......................................... 12

3.2 Experiments performed for trace metal partitioning studies.......................................14

3.3 Fuel Compositions ..................................................................................................................... 16

3.4 Temperature Profiles ......................................................................................................... 16

3.5 Health effects engineering studies-Methods and materials .......................................... 18

3.6 Particulate sources and reagents....................................................................................19

3.7 Particulate Sampling from Combustor ........................................................................ 21

3.8 Particulate Re-suspension/Characterization.............................................................. 21

3.9 Animals and Exposure ................................................................................................... 21

3.10 Lung Permeability and Pulmonary Functions.............................................................. 22

3.11 Bronchoalveolar Lavage Analysis...................................................................................... 22

4.0 RESULTS AND DISCUSSION ...........................................................................................23

4.1 Partitioning Studies............................................................................................................. 23

4.1.1 Particle size distributions........................................................................................... 23

4.1.2 Elemental Analyses............................................................................................... 26

4.1.3 Elemental Partitioning .......................................................................................... 26

4.2 Vapor-to-solid Phase Partitioning Mechanism ..............................................................29

4.2.1 Arsenic Surface Reaction Mechanisms...................................................................31

4.2.2 Antimony Surface Reaction Mechanisms............................................................37

4.2.3 Selenium Surface reaction Mechanisms ................................................................. 40

4.2.4 Zinc Surface Reaction Mechanisms ....................................................................... 43

4.3 Health Effects Engineering Studies ................................................................................. 44

4.3.1 Coal Only and MSS only (with Gas Assist) ...........................................................4 46

4.3.2 Doped distillate oil: zinc and zine plus sulfur .................................................... 46

4.3.3 Health effects engineering to diminish lung injury from inhaled particles... 48

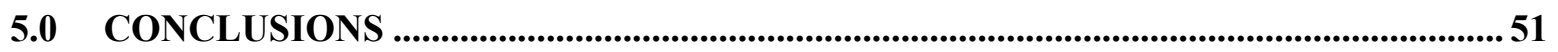

REFERENCES..................................................................................................................52 


\section{LIST OF FIGURES}

Figure 1: Initial test showing potential lung injury due to inhalation of ash aerosol from co-combustion of coal and MSS ......................................................... 8

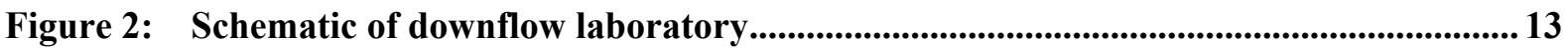

Figure 3: Particle sampling and size segregation system............................................................. 14

Figure 4: Measured temperature profiles for MSS and coal combustion runs .......................... 18

Figure 5: Schematic of downflow combustor configuration used for health effects

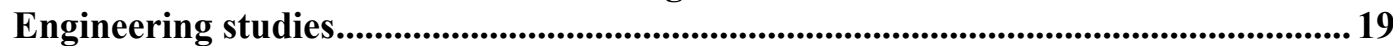

Figure 6: Average flue gas temperature profile of the nominally $18 \mathrm{KW}$ downflow Laboratory combustor burning doped distillate fuel oil. ......................................... 20

Figure 7: Differential particle size distributions based on measured weights on Each stage for 1) Natural Gas only; 2) MSS+NG; 3)Ohio Coal+MSS;

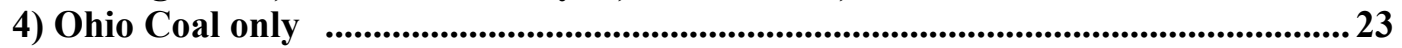

Figure 8: Elemental PSD's: Si, Ca, Fe and Al for mass PSD's shown on Fig.7 f........................... 25

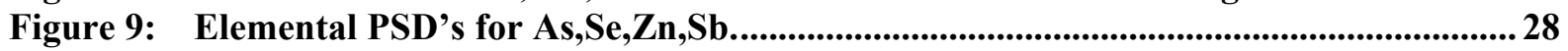

Figure 10: Net trace element differential distribution ............................................................................ 29

Figure 11: Dependence of trace metal concentration on particle size for super-

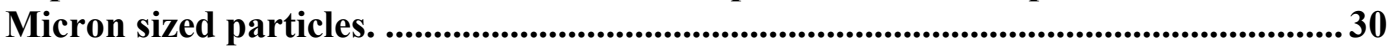

Figure 12: Comparison of arsenic to cation distributions ..................................................................... 32

Figure 13: Cross correlation of absolute concentrations of arsenic vs. calcium,

And arsenic vs. iron for super-micron particles ..................................................................... 33

Figure 14: MSS with gas assist. Cross correlation of differential elemental

Distributions, As vs $\mathrm{Ca}$ and As vs Fe in supermicron region ........................................34

Figure 15: MSS+Coal. Cross correlation of differential elemental

Distributions, As vs Ca and As vs Fe in supermicron region ......................................35

Figure 16: Additional cross-correlation details. ...............................................................................36

Figure 17: Antimony. Comparison to major element distributions. ............................................... 38

Figure 18: Comparison of Selenium to cation distributions................................................................. 41

Figure 19: Comparison of Zinc to major elements distributions..................................................... 43

Figure 20: Lung permeability due to inhaled coal ash and MSS ash. Temporal

Progression of lung permeability for exposures of 1 hour each day

For $1,3,12$, and 24 days

Figure 21: Particle size distributions of sampled particles from combustion of

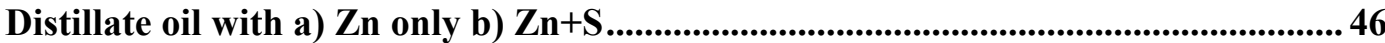

Figure 22: Doped distillate oil ash: lung permeabilities for $\mathrm{ZnO}$ aerosol and $\mathrm{ZnSO}_{4}$ Aerosol (lower) for various exposure periods. ................................................................. 47

Figure 23: Particle PSD's with kaolinite sorbent added ................................................................... 49

Figure 24: Elemental PSD of sampled ash with kaolinite sorbent injected into post-flame........ 49

Figure 25: Composition/particle size dependence for large zinc containing particles after

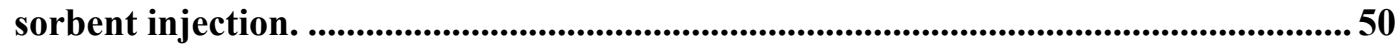

Figure 26: Lung permeabilities for larger sized inhaled particles. .............................................50 


\section{LIST OF TABLES}

Table 1: A summary of the MSS trace metal partitioning experiments ...................................... 15

Table 2: Summary of experimental sampling conditions for runs noted on Table 1................... 16

Table 3: MSS. Ohio Coal (trace element partitioning studies) and Gottelborn Coal (health effects studies) compositions ................................................................................... 17

Table 4: Partitioning of inorganic elements during mass experiments......................................27

Table 5: Correlation Coefficients for Antimony vs. Calcium, Iron, and Aluminum in Fly Ash Particles from the MSS Experiments. .......................................................... 39

Table 6: Correlation Coefficients for Selenium vs. Calcium and Iron in Fly Ash Particles from the MSS Experiments ........................................................................... 42

Table 7: Correlation Coefficients for Zinc vs. Calcium, Iron, and Aluminum in Fly Ash Particles from the MSS Experiments................................................................45 


\section{$1.0 \quad$ INTRODUCTION}

Municipal sewage sludge (MSS) is formed during wastewater treatment. Sludge is the largest byproduct of wastewater treating plants and it's processing and disposal represent one of the most environmentally challenging aspects of the wastewater treating process (Werther and Ogada, 1999). As discharged, the sludge is contained in a dilute $(0.25$ to $12 \mathrm{wt} \%)$ aqueous suspension and contains hazardous compounds. A description of how sludge is generated can be found in Werther, and Ogada (1999).

One of the options currently being considered to improve the treatment of this sludge is a process involving heat treatment (to render the sludge biologically inactive) followed by dewatering, drying, pulverizing, and combustion (Hall, 1992). The advantages of this combustion process are: a large reduction in disposal volume, thermal destruction of toxic organics, and recovery of the energy value of the carbon sources in the sludge (Werther and Ogada 1999). However, there are a number of potential disadvantages including NOx formation (due to the high nitrogen content of most MSS), handling of the raw material (due to the toxicity of metals and dioxins in the feedstock), possible boiler slagging and fouling problems (due to the high inorganic content of the feedstock), and the release of toxic trace elements into the environment (Cenni, et. al., 1998).

This work is directed towards two issues. First, a study was conducted to investigate the partitioning characteristics of selected trace elements during the combustion of a dried, treated (Swiss Combi Process), and pulverized MSS, at commercially relevant temperatures (i.e. combustion zone and post-combustion zone temperatures similar to those expected in commercial combustors. The objectives of this part of the study were:

- $\quad$ to quantify the partitioning of selected major inorganic (silicon, iron, calcium, and aluminum) and trace elements (zinc, arsenic, selenium, and antimony) during combustion of MSS in a natural gas flame

- to quantify the partitioning of selected major inorganic (silicon, iron, calcium, and aluminum) and trace elements (zinc, arsenic, selenium, and antimony) during cocombustion of MSS with a well-characterized bituminous coal (Ohio 5/6/7 blend)

- $\quad$ to identify mechanisms where possible for trace element vapor-to-solid phase partitioning

- to explore synergistic effects for co-combustion of MSS with coal

The second issue was motivated by the work of Fernandez et al., (2001). These authors investigated the effects of inhaling particles emitted from the co-combustion of MSS and coal. They found that these cause significantly more lung damage in mice than do particles from coal alone, probably because of their zinc content. Potential lung damage, in this case, was quantified by measurements comparing lung permeability of mice exposed to re-suspended ash particles to that of mice exposed only to room air. MSS had been processed (Swiss "Combi" process) to 


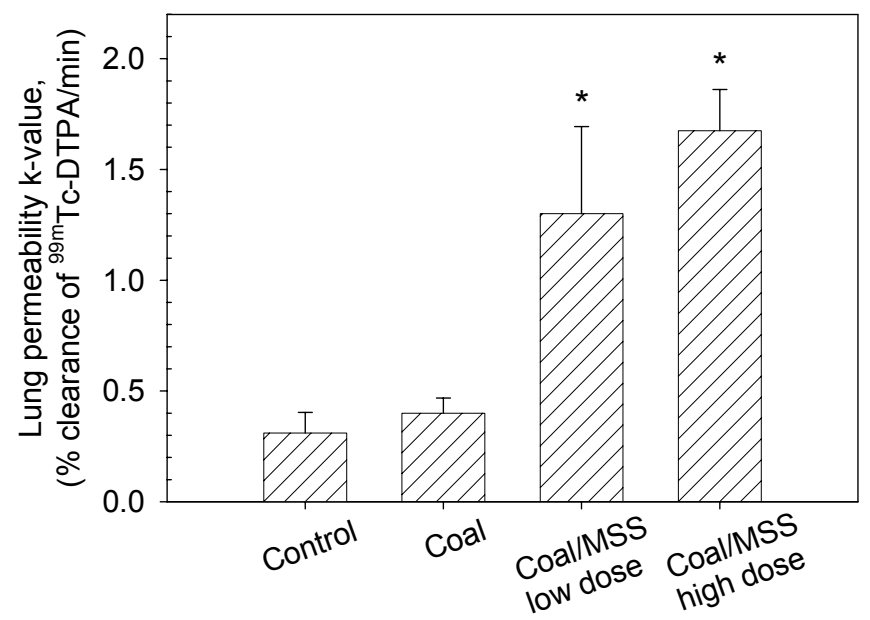

Figure 1. Initial tests showing potential lung injury due to inhalation of ash aerosol from co-combustion of coal and MSS.

produce 2-4-mm pellets, which were then pulverized and mixed (20\% thermal, 50\% mass load) with coal. Sampled particulate matter was re-suspended and diluted (Fernandez et al., 2002) to a sufficiently low concentration to allow the effects caused by different particle properties to be assessed on exposed mice. Mice were exposed for only 1 hour each day for 24 consecutive days to a low dose of $1,000 \mu \mathrm{g} \mathrm{m}^{-3}$ and to a high dose of $3,000 \mu \mathrm{g} \mathrm{m}^{-3}$ (the atmospheric dose of particulate matter less than $10 \mu \mathrm{m}$ in diameter currently allowed by the United States Environmental Protection Agency is $150 \mu \mathrm{g} \mathrm{m}^{-3}$ averaged over 24 hours). These results are shown on Fig. 1, and show that inhalation of coal ash alone yields results similar to those tests with room air, while inhalation of ash from co-combustion of coal and MSS, led to greatly increased lung permeability where the increase was dependent on dose. One concludes from this that the use of dried municipal sewage sludge as a "green" $\left(\mathrm{CO}_{2}\right.$-neutral) replacement fuel should be considered with caution.

Airborne particulate matter is associated with acute respiratory distress in humans (Dockery, 1993). Suggested causes (Lighty et al, 2000) of the lung damage caused by these particles include their composition - for example, they may contain soluble transition metals such as copper, iron, vanadium, nickel or zinc - their acidity, and their ultra-fine size (some particles are less than $0.1 \mu \mathrm{m}$ in diameter). These properties are all features of airborne particulate matter resulting from the co-combustion of pulverized coal and biomass, including dried municipal sewage sludge (MSS). Therefore it was of interest to determine if and why the combustion of MSS in general might lead to increased risk to human health, and if so, how that risk could be diminished through changes in the combustion process. To this end, the methods of Health Effects Engineering were employed, as described below.

Elemental analysis of the re-suspended coal/MSS ash particles revealed that $\mathrm{Zn}$ was more concentrated in those ash particles with sizes in the respirable particle size range. Since these studies indicated that $\mathrm{Zn}$ plays an important role in the toxic effects in ambient aerosols, another goal of this study was to investigate the inhalation response to systematically generated 
combustion ash particles containing Zn. The Health Effects Engineering component of the work was to determine the lung injury due to inhalation of systematically generated ash particles from two different fuels, namely distilled fuel oil doped with $\mathrm{Zn}$ only, and distillate oil doped with both $\mathrm{Zn}$ and sulfur, and from two different combustion configurations, namely with and without sorbent injection.

Health effects of zinc enriched particles have been studied in the literature. The formation of sulfated compounds on the surface of ash particles is of great importance. $\mathrm{Zn}$ is considered a trace metal in coal, accounting for approximately $2 \%$ of the total aerosol mass (Amdur et al, 1986). However, since $\mathrm{Zn}$ condenses on the surface of ash particles (presumably as zinc oxide which reacts with sulfur dioxide to from zinc sulfate), the higher concentration of this salt on the ash particle surface can have a significant impact on its bioavailability. It has been shown in several in-vitro studies that bioavailable metals can significantly contribute to cell toxicity and pulmonary hypertension (Prahalad, et al 1999, Ghio et al, 1999, Adamson et al, 1999, Costa et al, 1997). The chemical and surface composition of combustion generated ash particles can have a complex impact on lung function and properties. An in-vivo inhalation experiment conducted by Amdur and Chen (1989) brought to light the possibility that zinc oxide (ZnO) particles coated with sulfuric acid cause a significant change in lung mechanical functions and increase the protein and neutrophils in the pulmonary lavage fluid. More recently, Adamson et al (2000) published findings from intratracheal installation of an atmospheric dust sample (EHC-93), which contained several metals. Adamson's findings indicated that the soluble $\mathrm{Zn}$ had induced an inflammatory response with some necrosis of alveolar Type I cells, an increase in protein concentration, and the total number of cells in the bronchoalveolar lavage fluid (BALF). 


\subsection{EXECUTIVE SUMMARY}

Municipal sewage sludge (MSS) is formed during wastewater treatment. Sludge is the largest byproduct of wastewater treating plants and it's processing and disposal represent one of the most environmentally challenging aspects of the wastewater treating process. One of the options currently being considered to improve the treatment of this sludge is a process involving heat treatment (to render the sludge biologically inactive) followed by dewatering, drying, pulverizing, and combustion. Combustion of MSS is also $\mathrm{CO}_{2}$ neutral, in that the carbon released by combustion is equal to that sequestered by the sludge during its formation, which occurs over short time scales. It might thus be considered a "green", $\mathrm{CO}_{2}$ neutral, biomass fuel. A study was conducted to investigate the partitioning characteristics of selected trace elements during the combustion of a dried, treated (Swiss Combi Process), and pulverized MSS at commercially relevant temperatures, and to determine the potential of increased adverse health effects due to inhalation of ash particles formed from combustion of MSS containing fuels.

The work was motivated by two previous pieces of research. The first piece of research is the work of Seames and Wendt (2000), who showed that partitioning mechanisms of trace metals from coal combustion could be inferred by investigating associations between trace and major elements as functions of particle size. For example, by looking at the correlation between arsenic and either calcium or iron levels, as a function of particle size class (as measured on an impactor, with or without significant sulfur present) it was possible to investigate domains in which arsenic was bound with calcium, domains where it was bound with iron, and domains where it escaped as the oxide. In this work, therefore experiments were performed to examine the partitioning of four trace elements (As, $\mathrm{Se}, \mathrm{Zn}$, and $\mathrm{Sb}$ ) during the combustion of MSS under two conditions: combustion with natural gas assist and co-fired on a 50-50 basis (based on heating value) with an Ohio blend coal.

Experimental work was conducted in a $6 \mathrm{~m}$ tall, $0.15 \mathrm{~m}$ ID vertical downflow laboratory combustor operated at a feed rate of $12.5 \mathrm{~kJ} / \mathrm{s}(42,800 \mathrm{BTU} / \mathrm{hr})$ for all feed sources. The furnace is designed to simulate the time/temperature histories and complex particle interactions of commercial-scale combustors while still providing a flow stream that is sufficiently well characterized to allow extraction of rates and mechanisms. This furnace is described in detail elsewhere (Seames, 2000).

Results show that MSS combustion generates substantial bulk fly ash. However, the overall effect of including MSS in combustion does not appreciably increase or decrease the vaporphase or submicron phase trace element mass loading. This is an important finding, since submicron particles have been implicated in adverse health effects. The vapor-to-solid phase partitioning of zinc does not appear to be transport process controlled under either combustion condition. By contrast, the vapor-to-solid phase partitioning of arsenic, selenium, and antimony is controlled by surface reaction with active surface sites during MSS combustion with either gas or coal. With gas assist, but without coal, these oxy-anions appear to react with both calcium and iron surface sites. During co-combustion with a high sulfur $\left(3.5 \mathrm{wt} \%\right.$ as $\mathrm{SO}_{2}$ ) Ohio coal, these oxy-anions appear to react with calcium surface sites. 
The second piece of research that motivated this work was the discovery that inhalation of ash from the co-combustion of municipal sewage sludge (MSS) and pulverized coal caused much greater lung damage in mice, as measured by lung permeability increases, than that of coal ash alone. An increase of lung permeability has been demonstrated to lead to lung injury and the subsequent easing of pollutants being able to pass into the bloodstream. The concentrations to which the mice were exposed were of the order of $1000 \mu \mathrm{g} / \mathrm{m}^{3}$, for 1 hour per day for each of 3 , 12 , and 24 days, and can be compared to old EPA standards of $150 \mu \mathrm{g} / \mathrm{m}^{3}$ continuous exposure over 24 hours. Additional work showed that, surprisingly, the ash from MSS combusted without coal (but with natural gas assist) had similar toxicological characteristics as that from coal. In other words, both the coal ash alone, and the MSS ash alone, were relatively benign, from an inhalation toxicological point of view, while the ash from the co-combustion of these two fuels was not. In all cases, there was a temporal effect on lung permeability. For coal ash and MSS ash alone, the permeability first decreased (probably because of inflammation) but then after a few days, recovered to the values of the control set. For ash from co-combustion of coal plus MSS, the permeability doubled or tripled after 24 days, compared to the control set, and led to permanent lung injury.

MSS contains substantial quantities of zinc but little sulfur, while coal contains sulfur but little zinc. Therefore, systematic experiments were conducted in the same downflow combustor described above, to determine the health effects of combustion generated zinc particles and zinc plus sulfur particles. These experiments involved the combustion of a distillate oil doped with zinc acetate and, as appropriate, thiophene. Zinc without sulfur led to ash with "normal" lung injury characteristics, as far as lung permeability was concerned. Zinc with sulfur added led to the "abnormal" behavior noted also in the coal +MSS experiments. Therefore the bad actor was identified to be zinc together with sulfur, and that was why the co-combustion of coal and MSS caused greater lung injury than the combustion of either fuel alone.

Additional work showed that "Health Effects Engineering", which is a form of engineering employing collaboration of both combustion engineers and health effects scientists, can also be used to diminish this health risk caused by burning fuels containing both zinc and sulfur. Injection of a kaolinite sorbent downstream of the flame, but above the $\mathrm{Zn}$ dew point, can sequester the Zn, and react it to form a new species which was shown to be relatively benign.

In conclusion, although the addition of MSS to coal does not necessarily increase the emission of sub-micron particulates, those that are emitted from this mixture are more toxic, probably because of the presence of sulfated zinc. Elimination of sulfur in the fuel will solve the problem, as will also the addition of kaolinite to scavenge vaporized zinc. The new field of "Health Effects Engineering" has been found to be useful in assessing the potential impact of burning municipal sewage sludge, and in devising engineering solutions to mitigating potential lung injury from inhalation of emitted particles. 


\subsection{EXPERIMENTAL}

\subsection{Experimental facilities for trace metal partitioning studies.}

Experimental work was conducted in a $6 \mathrm{~m}$ tall, $0.15 \mathrm{~m}$ ID vertical downflow aerosol furnace (Fig 2) operated at a feed rate of $12.5 \mathrm{~kJ} / \mathrm{s} \quad(42,800 \mathrm{BTU} / \mathrm{hr})$ for all feed sources. The furnace is designed to simulate the time/temperature histories and complex particle interactions of commercial-scale combustors while still providing a flow stream that is sufficiently well characterized to allow extraction of rates and mechanisms. This furnace is described in detail elsewhere (Seames, 2000). Natural gas was premixed with air in the body of a laminar flame burner prior to discharge and ignition. MSS was fed using a volumetric screwfeeder. The MSS was blown off the screw tip and into the furnace using a metered stream of 5 psig transport air and then premixed first with the combustion air and then with the natural gas prior to ignition in the furnace. For coal combustion, coal was also fed using a volumetric screwfeeder. Coals was blown off the screw tip and into the furnace using a metered stream of 5 psig, transport air, then mixed with the primary air prior to discharge into the furnace. When both coal and MSS were burned, the primary air was first mixed with the coal, then with the MSS in the burner prior to discharge and ignition in the furnace. Coal and MSS were blended as a 50-50 mixture based on heat load (i.e. $\sim 6.3 \mathrm{~kJ} / \mathrm{s}$ for each fuel feedstock).

All of the experiments were run at a naturally evolving temperature profile and $20 \%$ excess oxygen in the combustion air. Fly ash particles were withdrawn from a sampling port (Port 14) located 4.3 meters below the burner. Samples collected at Port 14 represent typical conditions late in the post-combustion zone.

Particle sampling was performed using a portable water-cooler aspirated sampling probe. Dilution nitrogen is fed to the sample tip and a vacuum pump is used to draw the nitrogen plus the furnace sample from the centerline of the furnace. The dilution nitrogen plus the cooling jacket on the probe serves to freeze subsequent reaction in the probe. It also condenses any species that will condense above atmospheric conditions (Davis, et. al., 1998). The sample is routed to a Berner-type low-pressure impactor (BLPI; Hillamo and Kauppinen, 1991). The bottom stage of the BLPI acts as a sonic orifice and controls the total flow rate through the impactor. By measuring this flow rate with a wet test meter prior to sampling, an isokinetic sampling rate can be calculated and then maintained by adjusting the amount of dilution nitrogen routed to the probe. This sampling system, shown in Fig. 3, and its utilization with the University of Arizona combustor is described in detail elsewhere (Seames, 2000).

Sample sets that most closely duplicated the typical ash mass particle size distribution were selected for elemental analysis. Arsenic, selenium, zinc, and antimony analyses were performed by graphite furnace atomic absorption spectroscopy (GFAA) at Arizona. Major species (i.e.. silicon, calcium, iron, aluminum, and magnesium) were analyzed by flame atomic absorption spectroscopy (AAS) at Arizona while sodium was analyzed by flame atomic emission spectroscopy (AES) at Arizona. 


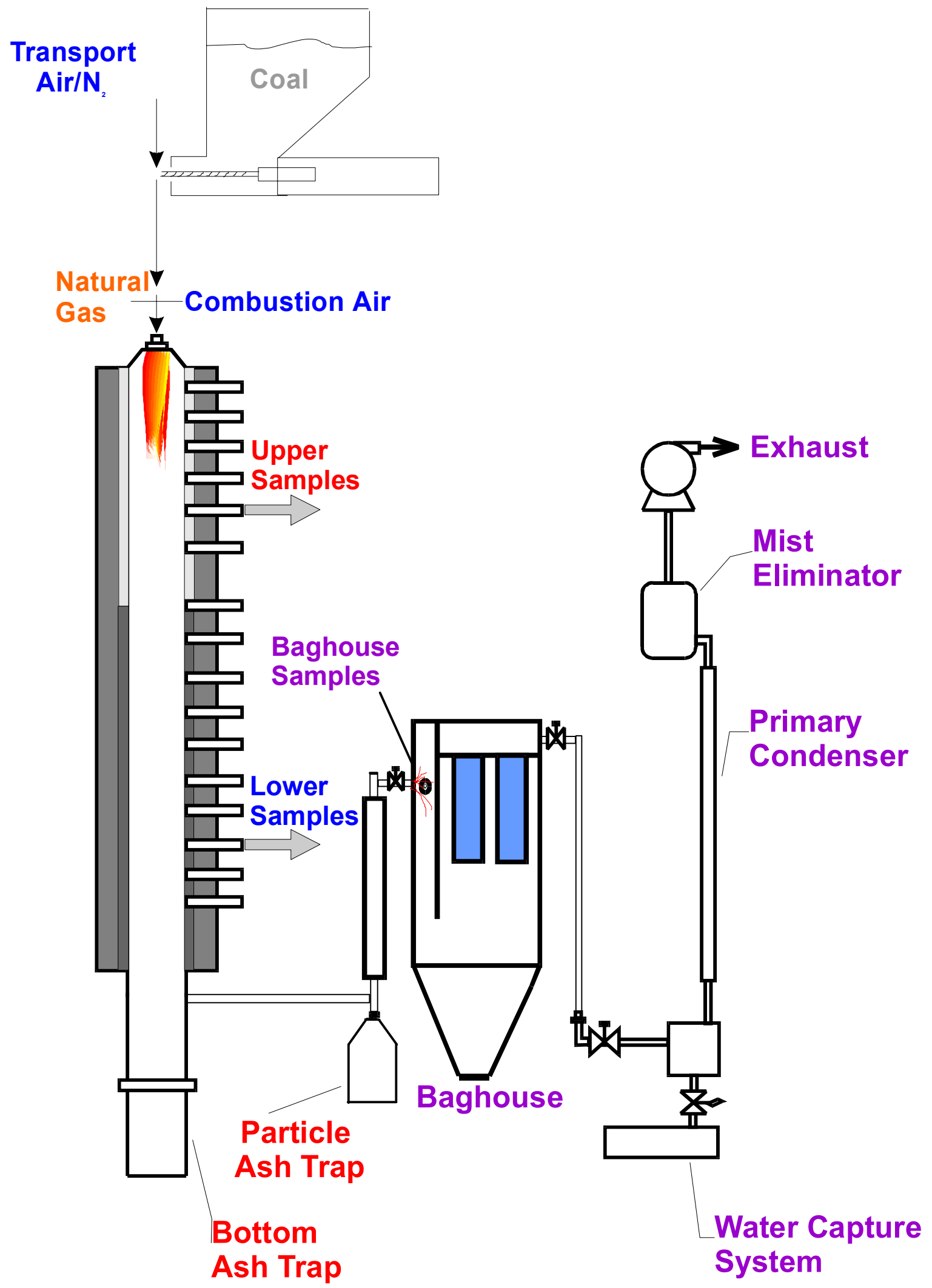

Figure 2. Schematic of downflow laboratory combustor 


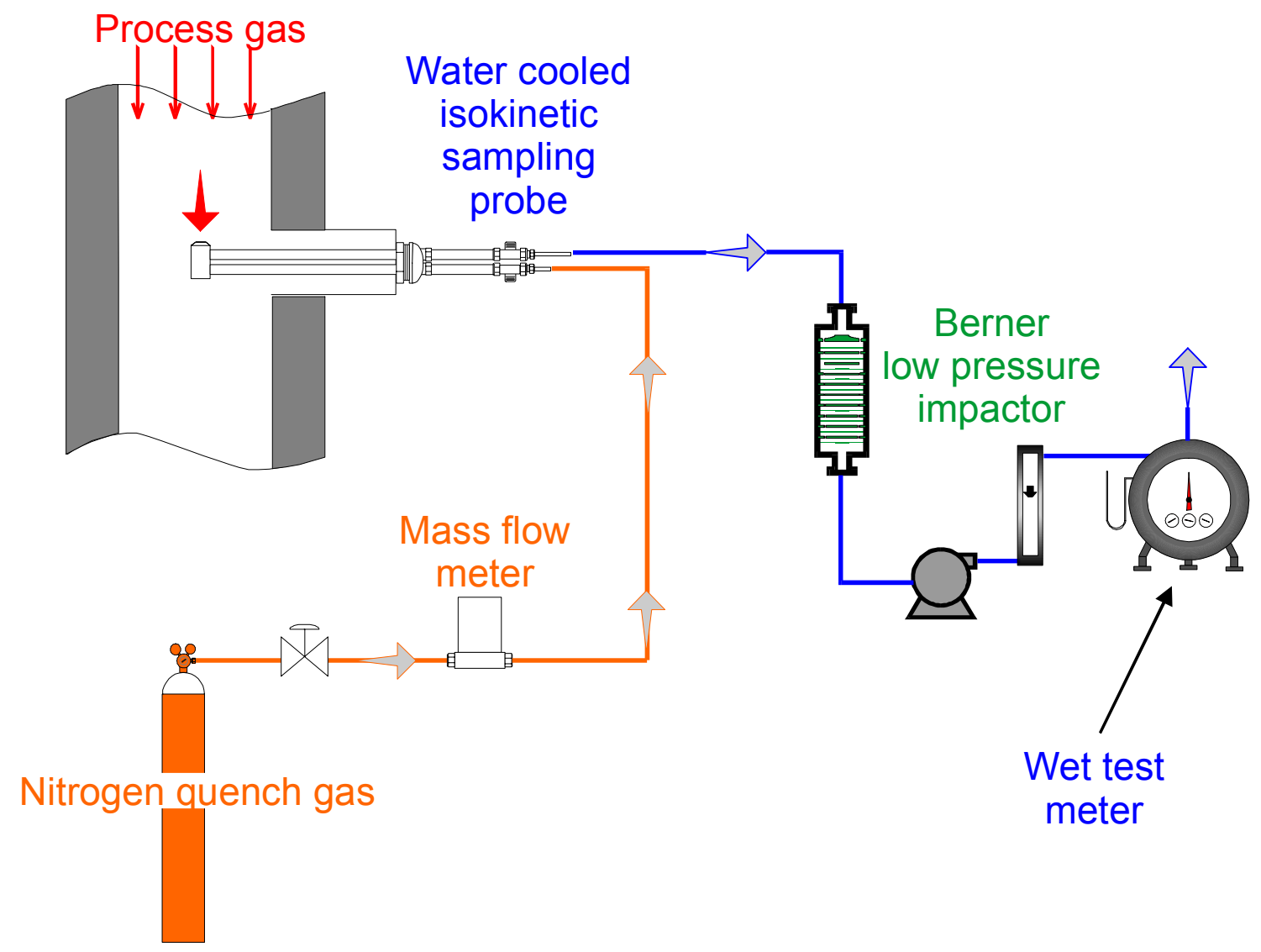

Figure 3. Particle sampling and size segregation system

\subsection{Experiments performed for trace metal partitioning studies}

A series of experiments were performed to meet the experimental objectives of this test program. A summary of the experiments performed is given in Table 1. Experimental conditions for the particle sample sets collected are summarized in Table 2. For the natural gas baseline experiment, one impactor set was collected at Port 14 (see Fig. 1) without using the inlet cyclone on the BLPI. For the other three test conditions (gas + MSS, coal only, coal + MSS), two matched impactor sets were collected at each test condition. A matched sample set consists of five membranes from a $1^{\text {st }}$ collection test for particulate on atmospheric stages -- 6-10 1 -- of the BLPI without the preseparator cyclone attached to the BLPI inlet and six membranes from a $2^{\text {nd }}$ collection test performed immediately before or after the $1^{\text {st }}$ test collecting particulate on the subatmospheric stages -- 1-6 -- of the BLPI with a cyclone.

The following sample sets were selected for inorganic analysis:

\footnotetext{
${ }^{1}$ A small number of particles were collected on the inlet membrane, stage 11. These were discarded and are not included in the results of this study.
} 


\section{Table 1}

A summary of the MSS trace metal partitioning experiments

\begin{tabular}{|c|c|c|c|c|c|c|}
\hline $\begin{array}{l}\text { Test } \\
\text { Run \# }\end{array}$ & Date & $\begin{array}{c}\text { Gas Feed } \\
\text { Rate } \\
\left(\mathrm{Nm}^{\wedge} 3 / \mathrm{hr}\right)\end{array}$ & $\begin{array}{c}\text { Coal Feed } \\
\text { Rate }(\mathrm{kg} / \mathrm{hr})\end{array}$ & $\begin{array}{c}\text { MSS Feed } \\
\text { Rate }(\mathrm{kg} / \mathrm{hr})\end{array}$ & $\begin{array}{l}\text { Sample } \\
\text { Set \# }\end{array}$ & $\begin{array}{l}\text { Sampling } \\
\text { Times }\end{array}$ \\
\hline \multirow[t]{5}{*}{$\underline{\text { MSS-1 }}$} & $05 / 11 / 00$ & $1.12^{2}$ & -- & -- & FB-1 & 60 mins \\
\hline & & 1.12 & -- & 1.36 & MSS-1c & 10 mins \\
\hline & & & & & MSS-1 & $30 \mathrm{secs}$ \\
\hline & & & & & MSS-2C & $10 \mathrm{mins}$ \\
\hline & & & & & MSS-2 & $30 \mathrm{secs}$ \\
\hline \multirow[t]{5}{*}{ MSS-2 } & $05 / 12 / 00$ & -- & 1.26 & 1.36 & MSS-3C & 10 mins \\
\hline & & & & & MSS-3 & $25 \mathrm{secs}$ \\
\hline & & & & & MSS-4c & 10 mins \\
\hline & & & & & MSS-4 & $1 \min 15$ \\
\hline & & & & & & secs \\
\hline \multirow[t]{4}{*}{ MSS-3 } & $05 / 13 / 00$ & -- & 1.58 & -- & MSS-5c & 15 mins \\
\hline & & & & & MSS-5 & 6 mins \\
\hline & & & & & MSS-6c & 15 mins \\
\hline & & & & & MSS-6 & 6 mins \\
\hline
\end{tabular}

${ }^{2}$ Assumes heating value of $40.24 \mathrm{MJ} / \mathrm{m}^{3}$ or $1080 \mathrm{Btu} / \mathrm{scf}$ 
Table 2

Summary of experimental sampling conditions for runs noted on Table 1

\begin{tabular}{|c|c|c|c|c|c|c|c|c|}
\hline $\begin{array}{c}\text { SAMPLE } \\
\text { SET \# }\end{array}$ & $\begin{array}{c}\text { TOTAL } \\
\text { COMBUSTION } \\
\text { GAS RATE } \\
(\text { slpm })\end{array}$ & $\begin{array}{l}\text { SAMPLIN } \\
\text { G RATE } \\
\text { (slpm) }\end{array}$ & $\begin{array}{l}\text { SAMPLIN } \\
\text { G TEMP. } \\
\left({ }^{\mathrm{o}} \mathrm{K} \text { at Port }\right. \\
\text { where } \\
\text { Sample } \\
\text { was taken) }\end{array}$ & $\begin{array}{c}\text { PORT } \\
4 \mathrm{O}_{2} \\
\mathrm{CONC} \\
(\%)\end{array}$ & $\begin{array}{c}\text { PORT } 4 \\
\mathrm{CO}_{2} \\
\mathrm{CONC} \\
(\%)\end{array}$ & $\begin{array}{c}\text { PORT } \\
14 \mathrm{O}_{2} \\
\mathrm{CONC} \\
(\%)\end{array}$ & $\begin{array}{c}\text { PORT } \\
14 \mathrm{CO}_{2} \\
\mathrm{CONC}^{(\%)}\end{array}$ & $\begin{array}{c}\text { PORT } \\
14 \text { NOx } \\
\text { CONC } \\
\text { (ppm) }\end{array}$ \\
\hline FB-1 & 261 & 2.48 & 891 & 2.9 & 10.2 & 5.1 & 9.1 & 127 \\
\hline MSS-1 & 265 & 2.58 & 905 & 3.1 & 12.3 & 4.7 & 11.3 & 812 \\
\hline MSS-2 & 265 & 2.58 & 905 & 3.1 & 12.3 & 5.6 & 10.4 & 780 \\
\hline MSS-3 & 262 & 2.17 & 1014 & 3.2 & 15.6 & 3.4 & 15.9 & 505 \\
\hline MSS-4 & 262 & 2.17 & 1014 & 2.9 & 15.8 & 3.4 & 15.9 & 505 \\
\hline MSS-5 & 250 & 2.03 & 916 & 3.4 & 15.8 & 3.5 & 15.9 & 640 \\
\hline MSS-6 & 250 & 2.03 & 916 & 3.4 & 15.8 & 3.5 & 15.9 & 640 \\
\hline
\end{tabular}

$\begin{array}{lll}\text { - } & \text { Natural gas only: } & \text { FB-1 } \\ \text { - } & \text { Gas + MSS: } & \text { MSS-2 } \\ \text { - } & \text { Coal Only: } & \text { MSS-6 } \\ \text { Coal + MSS: } & \text { MSS-4 }\end{array}$

\subsection{Fuel Compositions}

Proximate/ultimate/heat of combustion analysis and detailed elemental characterization of the Ohio 5/6/7 blend coal used in this study were performed by a consortium of researchers under DOE program DE-AC22-95PC95101, "Toxic Substances from Coal Combustion - A Comprehensive Assessment", (Senior, 1998). These data are shown in Table 3. MSS was prepared and provided by the Institute for Process Engineering and Power Plant Technology at the University of Suttgart (K. R. G. Hein, Director) by W. Scheurer and is representative of a typical German urban MSS (Scheurer, 1999). Proximate/ultimate/heat of combustion analysis of the MSS was performed at Galbraith laboratories (Knoxville, TN). Inorganic elemental analysis was performed at Arizona. These data are also shown in Table 3.

\subsection{Temperature Profiles}

Furnace temperature profiles were obtained for each test condition (excluding the gas only test condition $^{3}$ ). These are shown in Figure 4 . The similarity of these curves is not surprising and verifies that all experiments were performed at nearly identical heat loads. Most importantly, the

\footnotetext{
${ }^{3}$ A typical gas-only temperature profile obtained at a similar heat load for the same combustion furnace can be found in Fig. 4.2 of Davis (1999).
} 
Table 3

MSS. Ohio Coal (trace element partitioning studies) and Gottelborn Coal (health effects studies) compositions

\begin{tabular}{|c|c|c|c|c|}
\hline Analysis & Units & MSS & $\begin{array}{l}\text { Ohio Blend } \\
\text { Coal }\end{array}$ & $\begin{array}{l}\text { Gottelborn } \\
\text { Coal }\end{array}$ \\
\hline $\begin{array}{l}\text { Heat of } \\
\text { combustion }\end{array}$ & $\mathrm{MJ} / \mathrm{Kg}$ & 6.647 & 29.9 & 30.52 \\
\hline \multicolumn{5}{|l|}{ Proximate } \\
\hline Moisture & wt $\%$ & 5.12 & 2.33 & 4.78 \\
\hline $\begin{array}{l}\text { Volatile } \\
\text { Matter }\end{array}$ & wt $\%$ & 39.20 & 39.19 & 39.20 \\
\hline Fixed carbon & wt $\%$ & 1.89 & 48.78 & \\
\hline \multicolumn{5}{|l|}{ Ultimate } \\
\hline Carbon & wt $\%$ & 19.70 & 71.07 & 73.36 \\
\hline Hydrogen & wt $\%$ & 3.08 & 5.07 & 4.82 \\
\hline Nitrogen & wt $\%$ & 2.22 & 1.37 & 0.98 \\
\hline Chlorine & wt $\%$ & 0.041 & 0.0974 & 0.17 \\
\hline Oxygen & wt $\%$ & not available & 10.17 & not available \\
\hline Sulfur & wt $\%$ & 0.59 & 2.62 & 1.14 \\
\hline Ash & wt $\%$ & 53.79 & 9.70 & 9.66 \\
\hline \multicolumn{5}{|c|}{ Ash composition } \\
\hline $\mathrm{Al}_{2} \mathrm{O}_{3}$ & wt $\%$ & 19 & 39.41 & 23.6 \\
\hline $\mathrm{CaO}$ & wt $\%$ & 8.8 & 2.24 & 2.7 \\
\hline $\mathrm{Fe}_{2} \mathrm{O}_{3}$ & wt \% & 15 & 13.03 & 12.5 \\
\hline $\mathrm{MgO}$ & wt $\%$ & 4.1 & 1.02 & 2.7 \\
\hline $\mathrm{Na}_{2} \mathrm{O}$ & wt $\%$ & 1.8 & 0.92 & 0.4 \\
\hline $\mathrm{SiO}_{2} *$ & wt $\%$ & 36 & 38.09 & 42.5 \\
\hline As & ppmw & 6.7 & $19 / 13.2^{4}$ & not available \\
\hline $\mathrm{Sb}$ & ppmw & 7.2 & $2.30 / 1.44$ & not available \\
\hline $\mathrm{Se}$ & ppmw & 3.3 & $1.4 / 1.32$ & not available \\
\hline $\mathrm{Zn}$ & ppmw & 664 & $39 / 16$ & 42.5 \\
\hline $\mathrm{K}_{2} \mathrm{O}$ & $\mathrm{wt} \%$ & not available & $0.25 / 0.1187$ & 3.1 \\
\hline $\mathrm{TiO}_{2}$ & wt $\%$ & not available & 2.04 & 1.0 \\
\hline $\mathrm{Cd}$ & ppmw & not available & $0.40 / 0.1$ & 0.8 \\
\hline $\mathrm{Cr}$ & ppmw & not available & $19.0 / 11.4$ & 35 \\
\hline $\mathrm{Cu}$ & ppmw & not available & $\mathrm{nd}^{5} / 7.1$ & 24 \\
\hline $\mathrm{Mn}$ & ppmw & not available & $19 / 15$ & 95 \\
\hline $\mathrm{Ni}$ & ppmw & not available & $\mathrm{nd} / 13$ & 24 \\
\hline $\mathrm{Pb}$ & ppmw & not available & $\mathrm{nd} / 6.8$ & 47 \\
\hline
\end{tabular}

\footnotetext{
${ }_{5}^{4}$ First value from Neutron Activation (MIT), second value from ICP-MS, ICP-AES (USGS) See Seames (2000)

${ }^{5}$ none detected
} 


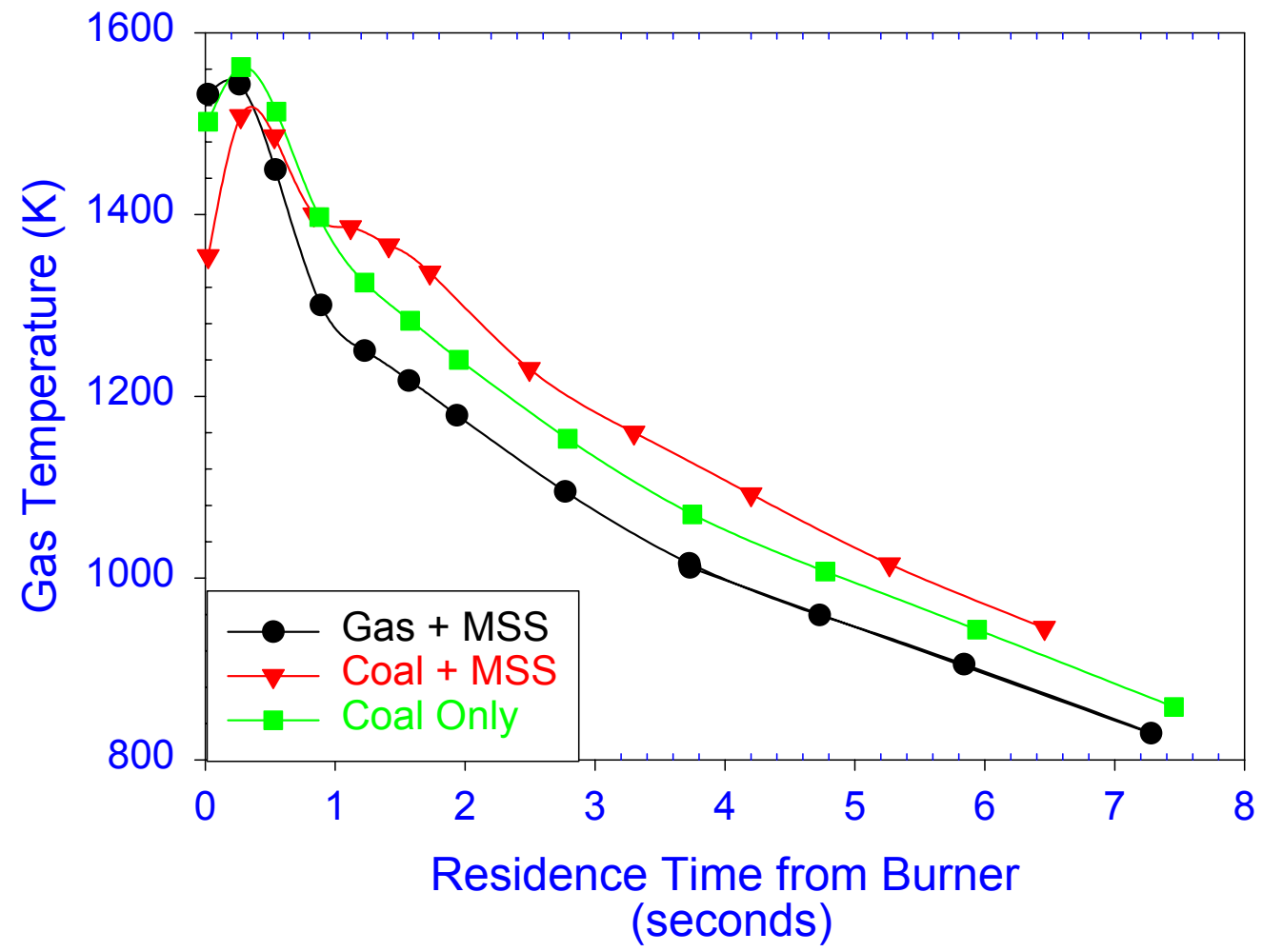

Figure 4. Measured temperature profiles for MSS and coal combustion runs.

maximum combustion temperature for each test is similar (within 60K). As the flue gas travels away from the burner, the rate of the temperature decrease measured is qualitatively consistent with the differences in the heat capacity of the three flue gas streams ${ }^{6}$.

\subsection{Health effects engineering studies- Methods and materials}

This section describes in detail just how closely Health Effects Engineering requires collaboration between combustion engineers and health effects scientists. Engineers determine the fuel compositions and process configurations to be tested while health effects scientists determine the consequences that these process changes will wreak on human health, upon inhalation of components in the exhaust. Health Effects Engineering therefore attempts to build a direct connection between the engineering facets of a process and the consequent effects on human health of any constituents produced. From engineering and toxicological points of view, the current work addresses the following, heretofore unresolved, issues: 1) Is fly ash from MSS alone (with natural gas assist) likely to cause more lung damage than fly ash from coal alone, or are there synergistic effects found in the co-combustion of coal and MSS together? 2) Does time resolution of exposures uncover some effects that perhaps were missed by the previous study? 3) Can the adverse health effects be mitigated by engineering changes of the process?

\footnotetext{
${ }^{6}$ Flue gas with higher particle loading with have higher heat capacity; for these tests MSS + Gas $<$ Coal Only $<$ Coal + MSS particle loading.
} 


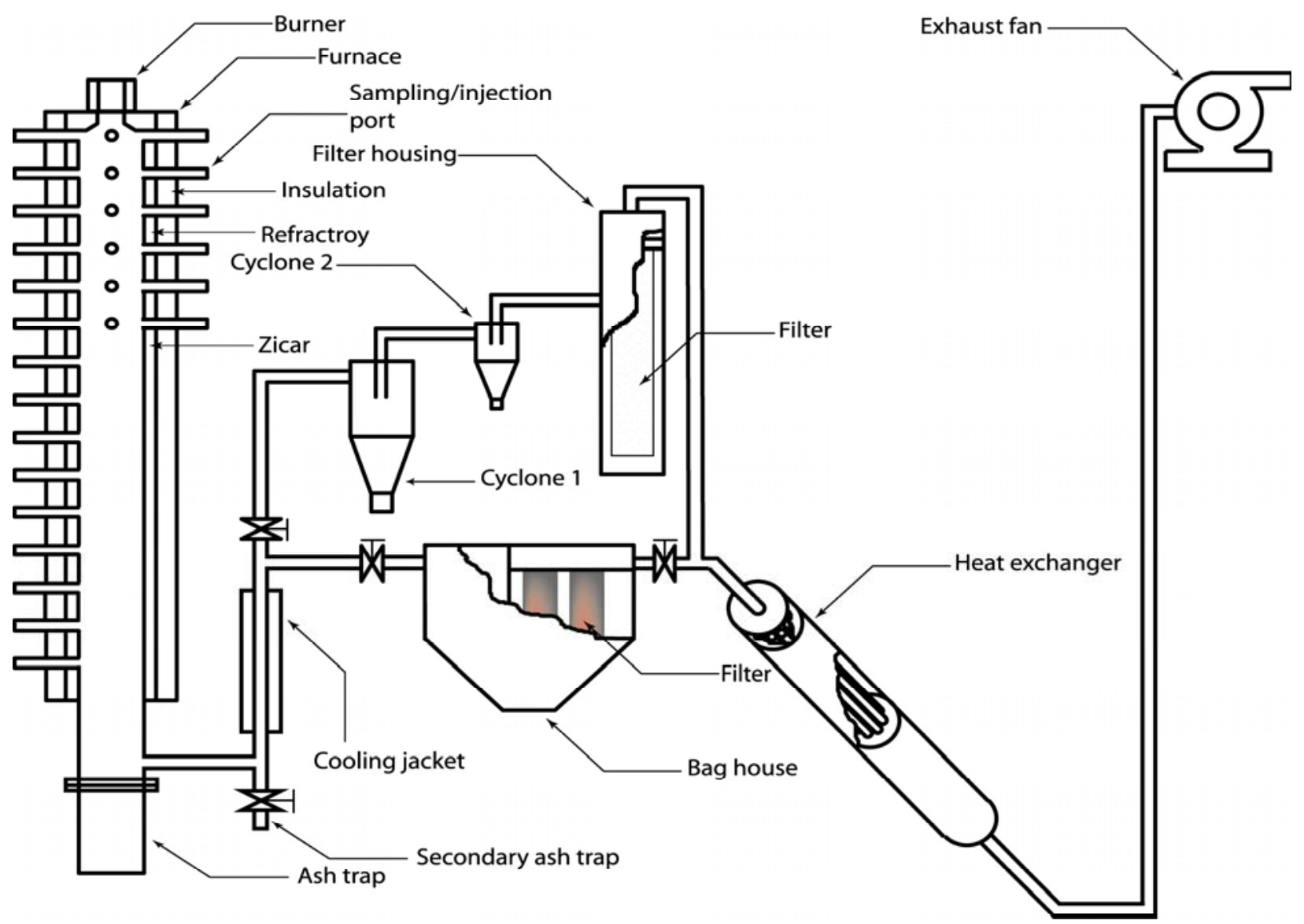

Figure 5. Schematic of downflow combustor configuration used for health effects engineering studies.

\subsection{Particulate sources and reagents.}

For the health effects studies involving coal ash, the coal was a German Göttelborn coal and the ash samples were provided by the Institute for Process Engineering and Power Plant Technology at the University of Stuttgart [12]. Combustion of coal was performed in an engineering R \& D scale, $500 \mathrm{~kW}$ downfired pulverized fuel combustor having a $0.75 \mathrm{~m}$ inner diameter and $\sim 7 \mathrm{~m}$ length. The first $4 \mathrm{~m}$ of the combustor were refractory lined while the remaining section was water cooled to simulate an industrial boiler section. The flue gas containing ash particles that were generated by the combustor passed through a bottoms hopper, air pre-heater $(T=550 \mathrm{~K})$, cyclone $(T=500 \mathrm{~K})$, and bag filter $(T=480 \mathrm{~K})$, respectively. Ash particles can be collected at the four previously listed locations. The ash particles used in the experiment as described in this paper were gathered at the surface of a baghouse filter, which exited the cyclone, and were reported to have a nominal mean diameter of $3.5 \mu \mathrm{m}$. Reference [12] gives a complete description of experimental procedures for the fuel combustion of coal and coal/MSS (municipal sewage sludge).

Samples for MSS assisted by natural gas were obtained combusted in the in-house (nominally) $18 \mathrm{~kW}$ laboratory scale, downfired pulverized fuel combustor described above. The feed rates of natural gas and MSS were $1.12 \mathrm{~m}^{3} / \mathrm{hr}$ and $1.36 \mathrm{Kg} / \mathrm{hr}$, respectively. Table 3 also provides 


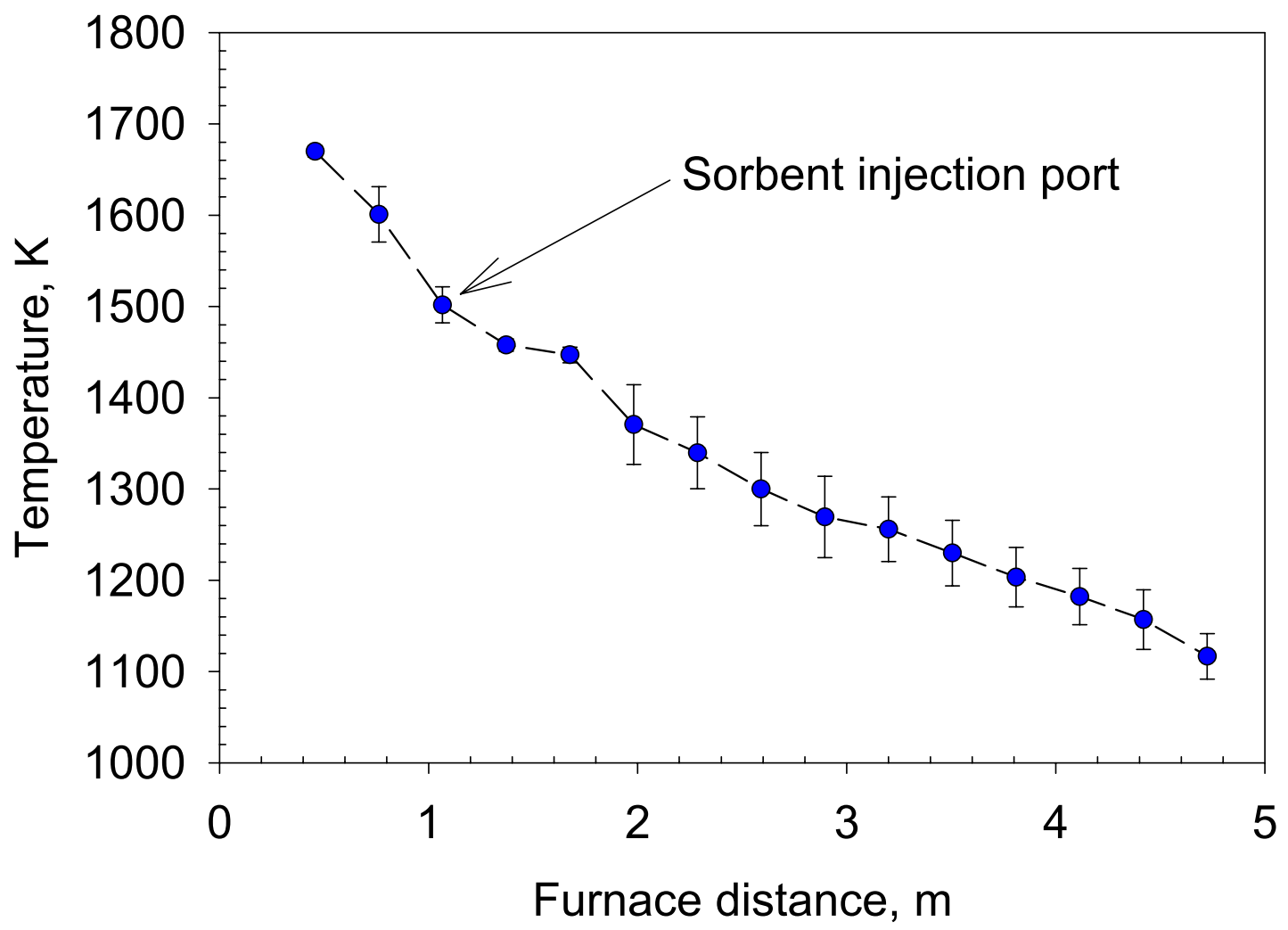

Figure 6: Average flue gas temperature profile of the nominally $18 \mathrm{~kW}$ downflow laboratory combustor burning doped distillate fuel oil. The bar indicates \pm one standard deviation. Sorhent iniection location and temnerature as shown.

chemical and elemental characteristics of the solid fuels (MSS and Göttelborn Coal) used for this study. The furnace exhaust was modified to allow the entire flue gas to be diverted through two

cyclones and a filter, from which bulk samples could be collected for subsequent re-suspension and exposure tests. This modified furnace is shown on Fig.5.

The health effects of combustion generated zinc particles were studied using the same (nominally) $18 \mathrm{~kW}$ downfired furnace, this time firing doped distillate oil and modified as shown on Fig. 6. 1.89 liters per hour of doped distilled fuel oil were introduced into top of the furnace. Depending on the experimental condition, the distilled fuel oil was also doped with zinc naphthenate and zinc naphthenate/thiophene. Thiophene is the compound containing S. The desired $\mathrm{Zn}$ and/or $\mathrm{S}$ concentrations of each element in the flue gas were $100 \mathrm{ppm}$. Furnace centerline temperature profiles, a typical example of which is shown on Fig. 6, were taken in all of the experiments with a bare wire, ceramic shielded, R-type thermocouple.

For the Health Effects Engineering tests directed towards mitigation of adverse health effects of combustion generated particulates, the effects of kaolinite sorbent injection were investigated. 1 gram per minute of sorbent Burgess 80 (B80) was injected at the centerline, 1 meter below from the top of the furnace, which was immediately after the post flame. Temperature data obtained 
from the measurements and point of sorbent injection are shown in Fig 6. The sorbent injection temperature was above the predicted dewpoint of $1350 \mathrm{~K}$, as determined from chemical equilibrium [13]. Furthermore, proper combustion conditions were monitored continuously by sampling the emissions of $\mathrm{CO}, \mathrm{CO}_{2}, \mathrm{O}_{2}$, and $\mathrm{NO}_{\mathrm{x}}$ gas concentrations. Chemical speciation of $\mathrm{Zn}$ and $\mathrm{Zn} / \mathrm{S}$ was also predicted by using Chemical Equilibrium Application (CEA) [13].

\subsection{Particulate Sampling from Combustor.}

Generated solid particles were withdrawn isokinetically from the centerline of the exhaust system of the furnace by a particle sampling probe. In order to separate zinc that had reacted with sorbent from zinc that was vapor in the combustor, the method of aerosol size fractionation [14] was employed. Here a rapid dilution quench at the tip of the sampling probe quickly converts all metal vapor present in the furnace at that point into ultrafine nuclei, which are then size segregated from the larger particles which captures zinc, using a Berner Low Pressure Impactor (BLPI). In order to collect particles in each stage of the LPI, polycarbonate substrates were utilized (K00CPARC00; Osmonics Inc). Prior to particulate collection, the substrates were sprayed with a mixture of 20 grams of Apeizon high-purity vacuum grease (Apeizon-L; Apeizon Products M\&I Materials LTD) mixed with 1 liter of hexane (39199; Alfa Aesar). Apeizon-L grease was needed to prevent particle bounce off [15]. For each particulate collection run, 10 grease-coated substrates were combined as batch then placed in an oven that was set to $70-75^{\circ} \mathrm{C}$ for 60 minutes. The elevated temperature helped to volatilize a significant amount of hexane. The desiccated substrates were then weighted three consecutive times in a mass balance (AP250D Analytical Plus Electronic Balance; Ohaus) prior and after particulate collection.

Since one of the goals of this experiment was to generate and collect particles for toxicological purposes, particles were collected on clone train (In-Tox, Albuquerque; NM) and a custom made filter system. The cyclone train consisted of two cyclones. The first cyclone was designed to remove particles larger then $10 \mu \mathrm{m}$ in diameter while cyclone two was designed to remove particles larger than $2 \mu \mathrm{m}$. The custom made filter system was capable of collecting particles larger than $0.5 \mu \mathrm{m}$ at $99 \%$ efficiency. The particles were collected on the surface of the filter. After several hours of running one type of experimental condition, the collected particles were removed and stored in a desiccated container until further use.

\subsection{Particulate Re-suspension/Characterization.}

A solid particle re-suspension system, which had been previously utilized to conduct similar toxicological studies, was employed [16]. The ash was re-suspended by a Palas RBG-1000 particle micro-flow feeder, and entrained into an air stream. The RBG-1000 was set at a prepressure of 2.5 bars $\left(2.5 \mathrm{~m}^{3} / \mathrm{hr}\right.$ flow rate) and a plunger travel rate of $1 \mathrm{~mm} / \mathrm{hr}$. The entrained aerosols were diluted to yield breathable air/particulate stream for direct inhalation, at concentrations of approximately $1000 \mu \mathrm{g} / \mathrm{m}^{3}$.

\subsection{Animals and Exposure.}

Seventy-two pathogen free mice, C57BL/6NHsd, were randomly divided into groups of eight $(30.0 \pm 4.3 \mathrm{~g})$. Of the seventy-two mice, fifty six (seven groups) were selected to be exposed to 
coal or MSS re-suspended ash particles. The other mice were used as experimental controls. The mice were housed 4 per cage with a 12-hr light/12-hr dark cycle at the Arizona Health Science Center animal facility (approved by the American Association for the Accreditation of Laboratory Animal Care) and fed a standard mice chow diet and tap water.

The re-suspended particulates were drawn through a 24-port nose-only exposure chamber (INTOX, Albuquerque, NM) using a constant vacuum ( $\sim 121 / \mathrm{min})$. The nose-only exposure system was utilized in order to minimize ingestion of particulate matter during grooming and to more closely simulate occupational exposure. Three groups of the experimental mice were exposed to re-suspended particulates (coal ash, MSS ash, $\mathrm{ZnO}$ or sulfated zinc ash, with and without kaolinite) particles for 1 hour/day for 3, 12, and 24 consecutive days. The control set of mice was exposed to ambient air only. In all of the particulate exposures, mice were exposed to a concentration of $\sim 1000 \mu \mathrm{g}$ of ash particles per cubic meter.

\subsection{Lung Permeability and Pulmonary Functions}

To exclude transient changes immediately following particulate exposure, analyses were performed 24 to $30 \mathrm{hr}$ after the final exposure. To ensure a deep state of anesthesia for the entire experimental period, the mice were anesthetized with an intramuscular injection mixture of ketamine HCL (80 mg/Kg; Parke-Davis, Morris Plains, NJ), xyline (10 mg/Kg; Mobay, Shawnee, KS), and acepromazine maleate (3 $\mathrm{mg} / \mathrm{Kg}$; Fermenta, Kansas City, MO). Tracheostomy was performed with the insertion of a Teflon intravenous catheter (20 gauge; Critikon, Tampa Bay, FL) serving as an endotracheal tube (Kent Scientific, Litchfield, CT). Airflow was measured with a pneumotachograph (Fleisch Instrumentation Associates) that was coupled to a differential pressure transducer (Validyne, Northridge, CA). Airflow and pressure signals were used to measure dynamic compliance. Pulmonary resistance was measured with a modified PEDS-LAB (Medical Associated Services, Hatfield, PA) pulmonary function system by the method of Rodarte and Rehder [17]. The mechanical pulmonary functions were recorded and normalized to the weight of each animal. They are not reported here for lack of space. Lung permeability was measured with a $100 \mu$ l endotracheal instillation of a $100 \mu \mathrm{Ci}{ }^{99 \mathrm{~m}_{\text {technitium }}}$ labeled diethylenetriamine pentaacetate $\left({ }^{99 \mathrm{~m}} \mathrm{Tc}-\mathrm{DTPA}, 492 \mathrm{amu}\right.$ and a physical half-life of 6.02 $\mathrm{hr}$ ) bolus, followed by five tidal volume breaths of ambient air to disperse the ${ }^{99 \mathrm{~m}} \mathrm{Tc}$-DTPA. Lung permeability was then determined by monitoring the pulmonary clearance of ${ }^{99 \mathrm{~m}} \mathrm{Tc}-\mathrm{DTPA}$ over ten minutes using a Ludlum Model 2000 gamma counter (Ludlum, Sweetwater, TX).

\subsection{Bronchoalveolar Lavage Analysis}

From each of the experimental groups normally four animals were selected for bronchoalveolar lavage. The washes were performed three times with $1 \mathrm{ml}$ aliquots of sterile $0.85 \%$ saline solution each time [18]. The mean saline recovery was approximately $85 \%$. The collected bronchoalveolar lavage fluid solution (BALF) was decanted into chilled polypropylene tubes and spun at $1000 \mathrm{rpm}$ for 10 minutes at $4{ }^{\circ} \mathrm{C}$. The supernatant was transferred from the cell pellet and stored at $-70{ }^{\circ} \mathrm{C}$ without preservative until further use for chemical mediator assays. Prior to spinning the BALF, approximately $100 \mu \mathrm{l}$ of the solution was placed in a hemocytometer and total cell count was performed under light microscopy. Biochemical assays, TNF- $\alpha$ and IL1- $\beta$ (Assay Designs, Inc.; 900-047 \& 900-041), were performed on the cell-free BALF. 


\subsection{RESULTS AND DISCUSSION}

\subsection{Partitioning Studies}

4.1.1 Particle size distributions The differential total ash particle distributions (PSDs) for all four experimental conditions are shown in Fig 7. These distributions were developed following a
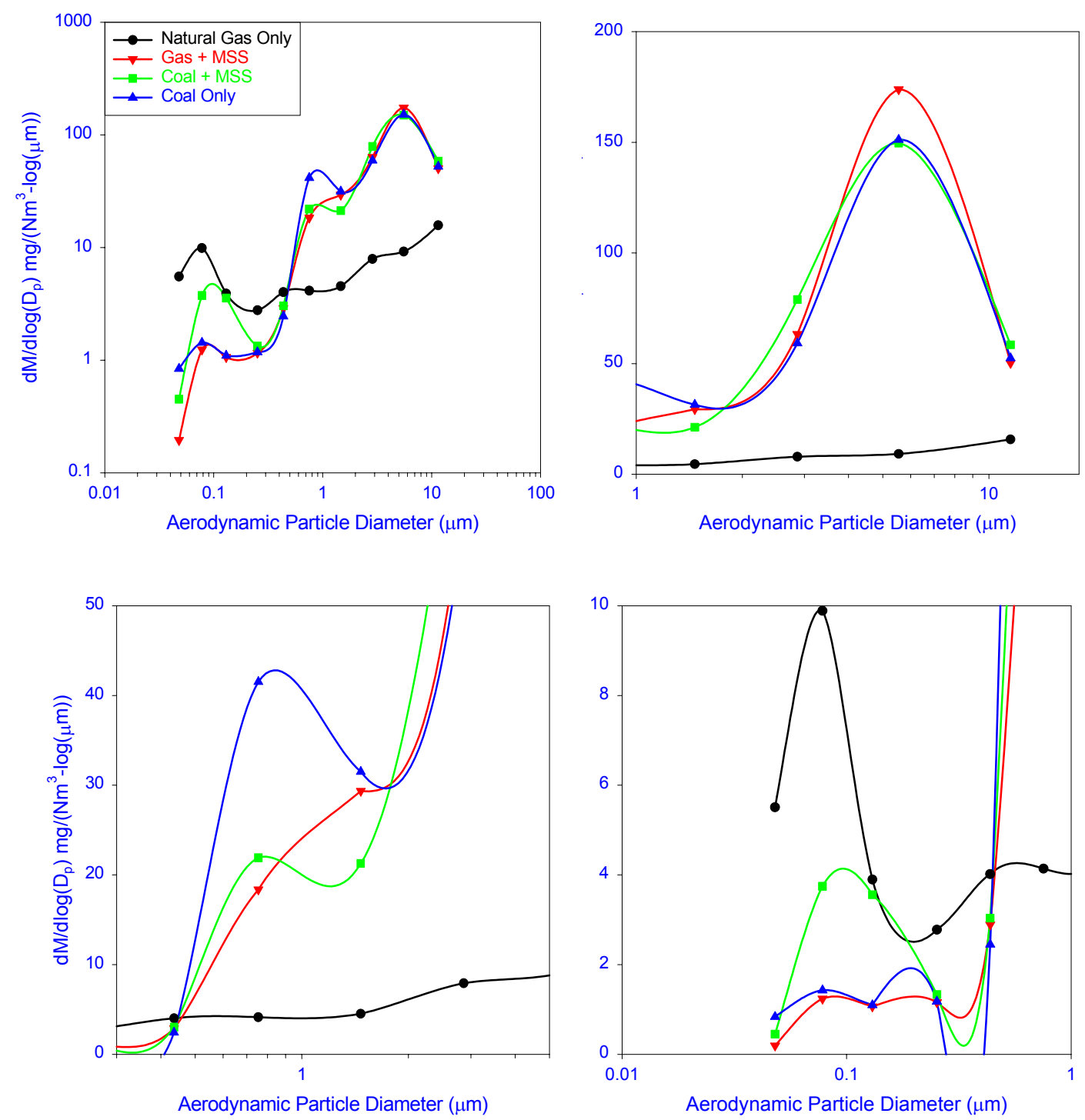

Figure 7. Differential particle size distributions based on measured weights on each stage for 1) Natural Gas only; 2) MSS+ NG; 3) Ohio Coal +MSS; 4) Ohio Coal only. Complete data on top left quadrant. Other quadrants emphasize specific particle size ranges.

method originally developed by Markowski and Ensor (1977) for reporting impactor results. The mass collected on an impactor stage is divided by the volume of gas passing through the impactor during the sampling period. Using this concentration value for each impactor stage, the differential concentration is divided by the differential $\log _{10}$ of the particle size. This value is 
plotted versus the average particle $\operatorname{size}^{7}$ associated with the differential particle size used. In Fig 7 , four different size scales are shown from the same data in order to evaluate different attributes of the same data.

Four distinct particle regions are evident for the "Coal only" and "Coal + MSS" results: a vaporphase region, a submicron fume region, a micron-sized "fragmentation" region, and a bulk ( $>$ $3 \mathrm{~mm}$ diameter) fly ash region. By contrast, the "Gas only" distribution shows only two distinct regions - a vapor-phase region and a particle region while the "Gas + MSS" distribution shows three regions - a vapor-phase region, a submicron region, and a supermicron region.

For the sampling system employed in this work, Davis, et. al. (1998) demonstrated that (for flue gases generated by the combustion of gas flames doped with 100 ppmv semi-volatile metals) the smallest particle sizes (below about 0.1 microns) in the profile primarily represent vapor-phase material that nucleates in the sample probe. The vapor-phase material represents a greater fraction of the total material for the "Gas only" sample compared to the other distributions. More noteworthy, the co-firing of MSS with coal increases the vapor-phase material compared to coal alone or MSS fired with gas assist.

The presence of a submicron fume region from pulverized coal combustion has been explored in detail by previous researchers. The major refractory elements ( $\mathrm{Fe}, \mathrm{Si}, \mathrm{Al}$, and $\mathrm{Ca}$ ) are believed to vaporize as suboxides formed by reduction with $\mathrm{CO}$ in the immediate vicinity of the burning char particle (Linak and Peterson, 1984; Senior and Flagan, 1982, McNallan, et. al., 1981). As the molecules diffuse out of the reducing atmosphere of the char, they are oxidized. These oxides are not very volatile and will nucleate while still in the flame zone to form a submicron fume (Mulholland and Sarofim, 1990; Sarofim, et.al., 1977; Natusch, et.al., 1974; Taylor and Flagan, 1982; Linak and Peterson, 1984; Helble and Sarofim, 1989, McNallan, et. al., 1981). The fractionation of larger particles to submicron-sized particles also contributes to the submicron fume (Smith, 1980, McNallan, et. al., 1981, Helble and Sarofim, 1989). The contribution from fractionation is highly fuel dependent. The submicron fume is typically only $1-7 \%$ of the total fly ash mass but has a very high particle number density (McNallan, et. al., 1981, Wall, et. al., 1979).

Profiles in the submicron region are similar for the "Gas + MSS", "Coal only", and "Coal + MSS" test conditions. Previous work has shown that during combustion of the Ohio 5/6/7 blend coal, the mechanisms responsible for submicron particle generation are consistent with the submicron fume theory described above (Seames, 2000). Thus the similarity in profiles between these three test conditions suggests that submicron fume theory is applicable during the combustion of MSS co-fired with gas or coal.

The near micron-sized "fragmentation" region has only been recently observed (Linak, et. al., 2000; Seames, 2000) during pulverized coal combustion. This regime is believed to form by the

${ }^{7}$ All of the impactor particle size data reported here is reported as the $50 \%$ cutoff aerodynamic particle diameter. Collection efficiency curves of the BLPI are reported elsewhere (Hillamo and Kauppinen, 1991). The relationship between the real diameter of a fly ash particle and the aerodynamic diameter is described elsewhere (Raask, 1981). 

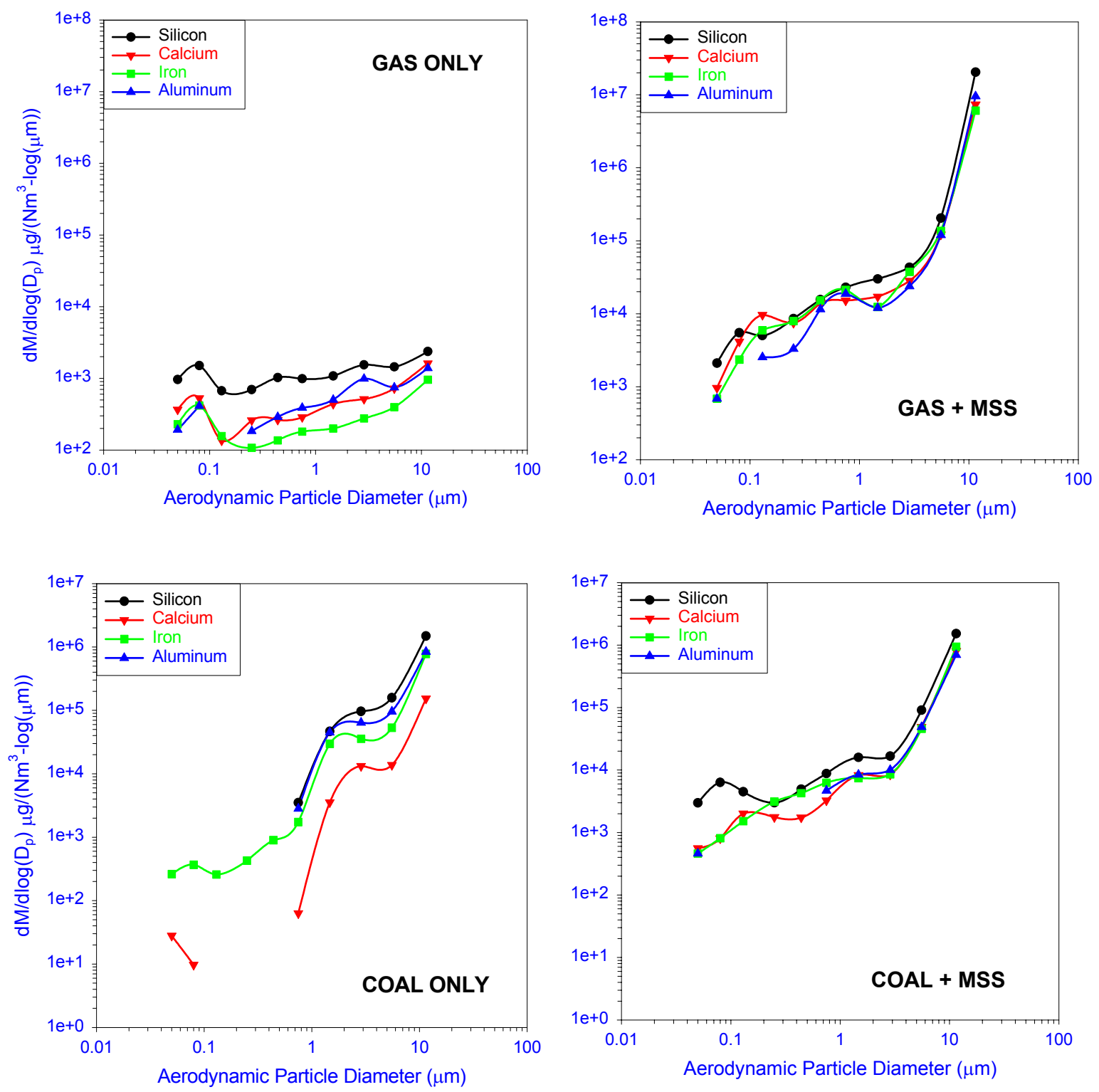

Figure 8. Elemental PSD's: Si, Ca, Fe and Al for mass PSD's shown on Fig 7.

swelling and fragmentation of larger particles (e.g. hollow cenospheres) during char burnout. Seames (2000) demonstrated that the partitioning mechanisms for volatilized trace elements (i.e. arsenic and selenium) could be different in the fragmentation region compared to the bulk fly ash region for some coal/combustion condition combinations. Co-combustion of MSS with coal results in a smaller fragmentation region compared to coal alone. This suggests that only the coal char particles are participating in the fragmentation mechanism. The absence of a fragmentation mode in the "Gas + MSS" PSD supports the conclusion that MSS ash particles are not subject to significant fragmentation leading to the generation of a micron-sized particle region. 
The bulk fly ash profiles for the "Gas + MSS", "Coal only", and "Coal + MSS" experiments are similar.

4.1.2 Elemental Analyses Differential elemental distributions for key major inorganic elements (i.e. Si, Ca, Fe, and Al) developed following the method of Markowski and Ensor (1977) are shown in Figure 8 for all four experimental conditions. Figure 9 shows the equivalent information for key trace elements (i.e. As, Se, $\mathrm{Zn}$, and Sb). The relatively low concentrations of calcium and aluminum in the Ohio coal shown in Fig 8 are consistent with previous results for this coal (Seames, 2000). Note the substantial increase in the submicron and vapor-phase concentrations of all major species when MSS is co-fired with coal compared to coal alone. The concentrations of major species in the vapor-phase and submicron regions is similar for the "Gas + MSS" and "Coal + MSS" profiles. This suggests that most of the material in these regions originated in the MSS feedstock.

Natural gas is a significant feedstock source for As and Se but not for Zn and Sb (see Figure 9). All four trace element profiles have a similar shape for the "Gas + MSS" results indicating similar partitioning mechanisms. By contrast, the zinc profile in the "Coal only" and "Coal + MSS" experiments are very different from the other three trace elements. The selenium profile for the "Coal + MSS" experiment is different from the arsenic and antimony profiles (which are similar). But in the "Coal only" experiment the As, Se, and Sb profiles are all similar. These results suggest that there may be differences in the partitioning mechanisms of some of these trace elements when MSS is co-fired with coal compared to coal-only combustion.

4.1.3 Elemental Partitioning The partitioning of major and trace elemental species between the vapor-phase region, submicron region, and the combined supermicron region (fragmentation plus bulk fly ash) is summarized in Table 4 . Over $98.7 \mathrm{wt} \%$ of the major elements is contained in the supermicron particles for all test conditions (excluding the gas only sample). There is a fairly significant increase in the fraction of selenium and zinc partitioning to the vapor-phase and submicron phases for the "Coal + MSS" test compared to the "Coal only" or "Gas + MSS" tests. By contrast, the fraction of arsenic partitioning to the small size regions is lower in the "Coal + MSS" test compared to the "Coal only" test.

Another way to view the impact of co-firing on trace element partitioning is to construct net trace element differential distributions. These are shown in Fig 10 for As, Se, Zn, and Sb. To construct these curves, the trace element concentration in micrograms per normal cubic meter $\left(\mu \mathrm{g} / \mathrm{Nm}^{3}\right)$ on a given impactor stage for the baseline case (Gas only or Coal only) was subtracted from the trace element concentration on the same impactor stage for the co-fired case (Gas + MSS or Coal + MSS). The net trace element concentration was then used to construct differential distributions following the method of Markowski and Ensor (1977). 
Table 4

Partitioning of inorganic elements during mss experiments

\begin{tabular}{|c|c|c|c|}
\hline $\begin{array}{r}\text { Experiment/ } \\
\text { Element }\end{array}$ & $\%$ in Vapor Phase & $\begin{array}{c}\% \text { in Submicron } \\
\text { Phase }\end{array}$ & $\begin{array}{c}\% \text { in Supermicron } \\
\text { Phase }\end{array}$ \\
\hline \multicolumn{4}{|l|}{ Natural Gas Only } \\
\hline Silicon & 21 & 20 & 59 \\
\hline Calcium & 16 & 14 & 70 \\
\hline Iron & 21 & 13 & 66 \\
\hline Aluminum & 9 & 15 & 76 \\
\hline Arsenic & 26 & 21 & 53 \\
\hline Selenium & 48 & 29 & 23 \\
\hline Zinc & 37 & 22 & 41 \\
\hline Antimony & 40 & 47 & 13 \\
\hline \multicolumn{4}{|l|}{ Gas + MSS } \\
\hline Silicon & 0.04 & 0.17 & 99.8 \\
\hline Calcium & 0.14 & 0.36 & 99.5 \\
\hline Iron & 0.10 & 0.53 & 99.4 \\
\hline Aluminum & 0.03 & 0.26 & 99.7 \\
\hline Arsenic & 0.36 & 0.53 & 99.1 \\
\hline Selenium & 0.94 & 1.03 & 98.1 \\
\hline Zinc & 0.81 & 0.49 & 98.7 \\
\hline Antimony & 0.14 & 0.33 & 99.5 \\
\hline \multicolumn{4}{|l|}{ Ohio Coal Only } \\
\hline Silicon & $n d^{8}$ & 0.16 & 99.8 \\
\hline Calcium & 0.02 & 0.03 & 99.9 \\
\hline Iron & 0.07 & 0.26 & 99.7 \\
\hline Aluminum & $\mathrm{Nd}$ & 0.22 & 99.8 \\
\hline Arsenic & 3.0 & 1.6 & 95.4 \\
\hline Selenium & 1.1 & 0.93 & 98.0 \\
\hline Zinc & 0.39 & 0.50 & 99.1 \\
\hline Antimony & 0.46 & 0.20 & 99.3 \\
\hline \multicolumn{4}{|l|}{ Coal + MSS } \\
\hline Silicon & 0.56 & 0.76 & 98.7 \\
\hline Calcium & 0.28 & 0.60 & 99.1 \\
\hline Iron & 0.20 & 1.03 & 98.8 \\
\hline Aluminum & 0.05 & 0.48 & 99.5 \\
\hline Arsenic & 1.8 & 1.6 & 96.6 \\
\hline Selenium & 9.7 & 5.9 & 84.4 \\
\hline Zinc & 3.6 & 4.8 & 91.6 \\
\hline Antimony & 0.91 & 1.9 & 97.2 \\
\hline
\end{tabular}

\footnotetext{
${ }^{8}$ nd = below detection limit
} 

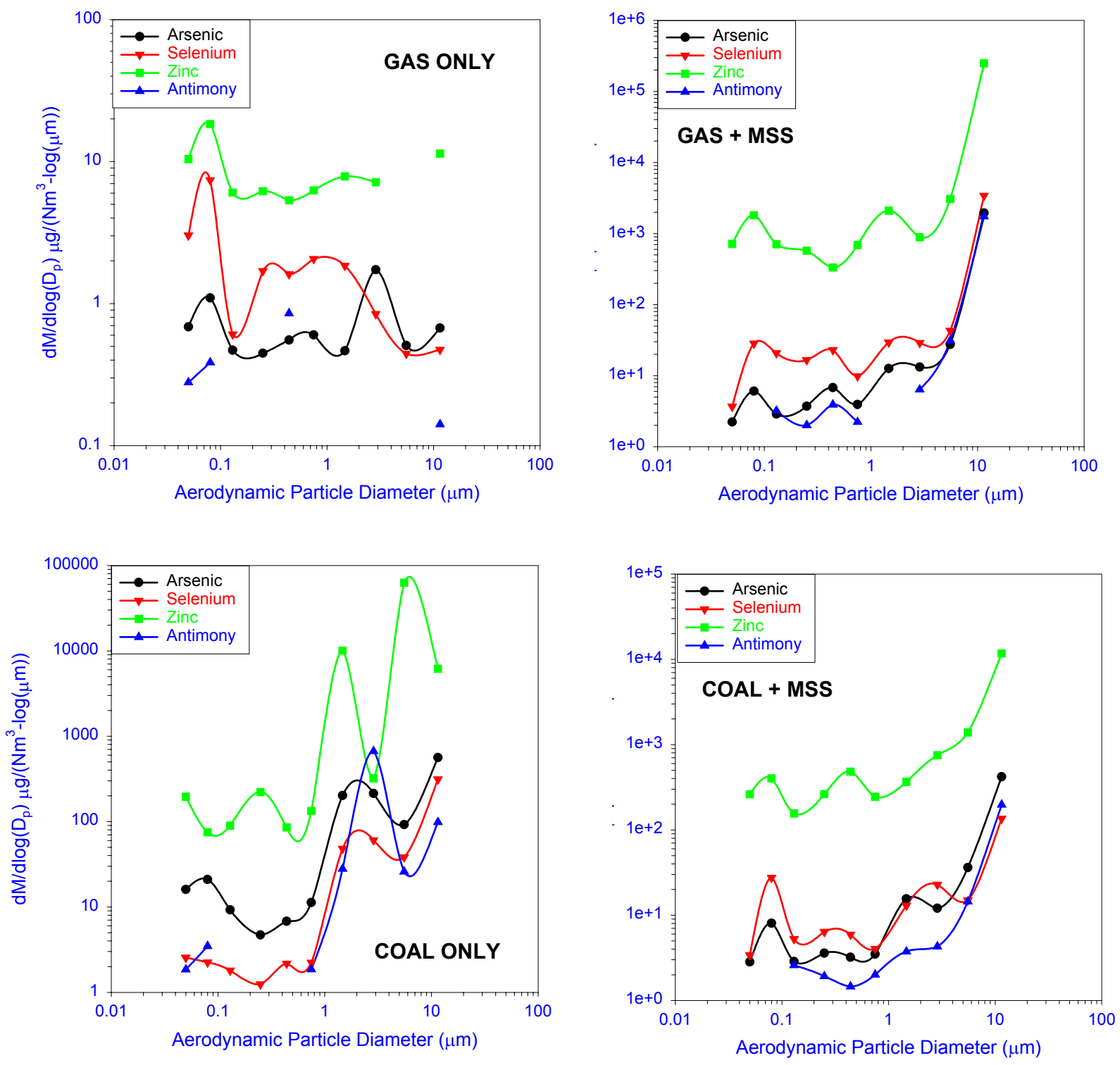

Figure 9. Elemental PSD's for As, Se, Zn, Sb.

For the "MSS + Gas" test, there is a net increase in the concentration of all trace elements compared to the "Gas only" test. The smallest increases are for arsenic and antimony (were the concentration in the "Gas only" test is of the same order of magnitude as the concentration in the "MSS + Gas" test - the natural gas utilized in these tests has a fairly significant As and Sb content).

For the "Coal + MSS" test, there is a substantial increase in the trace elements in the bulk fly ash region. There is no appreciable difference in the vapor-phase and submicron phase concentrations. These results imply that there is no appreciable "scavenging" effect in co-firing MSS with this coal. In absolute terms, there is no substantial impact on trace element partitioning when MSS is co-fired with this Ohio coal. 

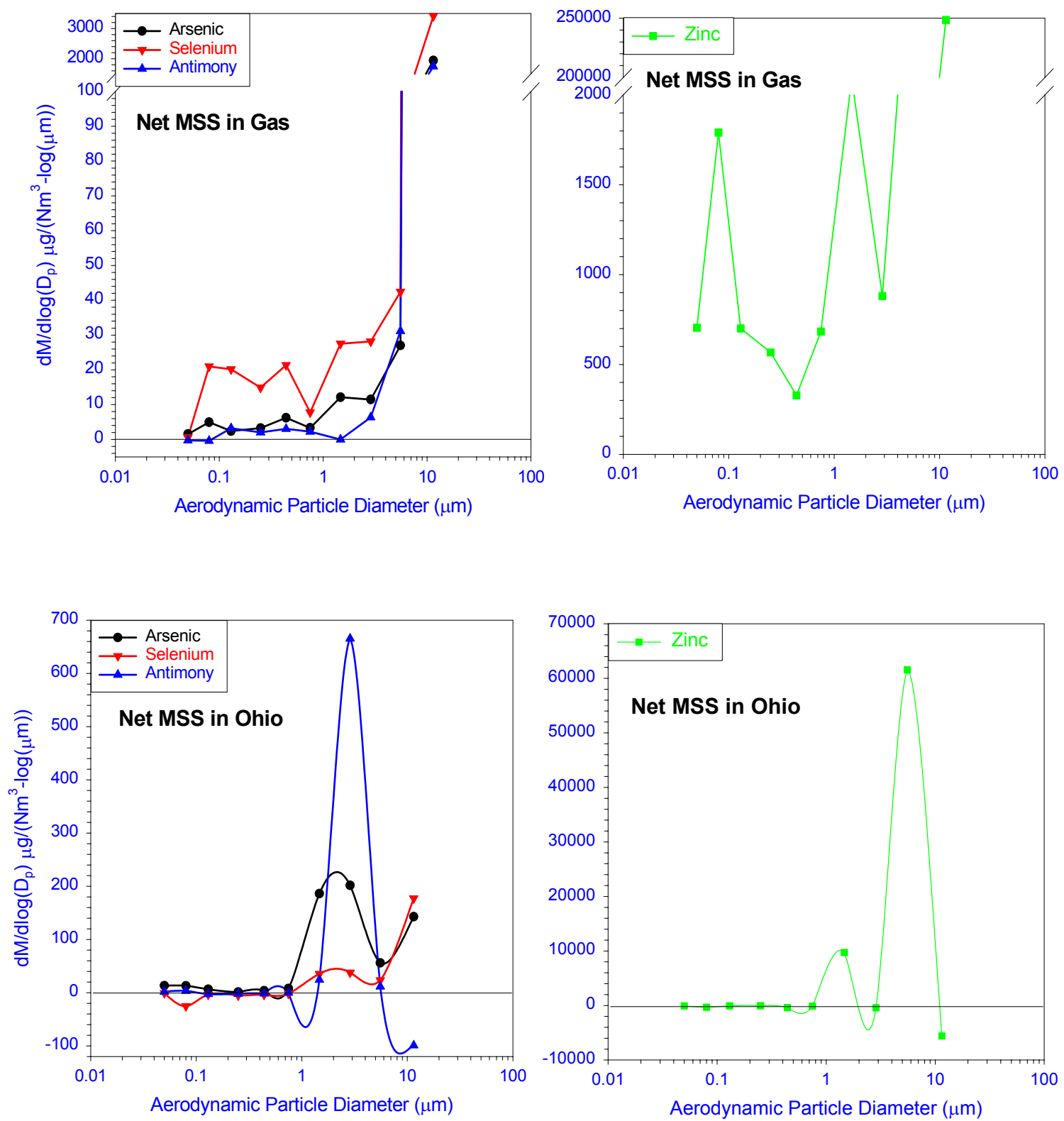

Figure 10. Net trace element differential distribution. Upper quadrants: Net trace element contribution from MSS with gas assist [ (MSS+NG)-NG]; Lower quadrants: Net trace element contribution from MSS during co-combustion with coal [(MSS+Coal)-Coal]

\subsection{Vapor-to-Solid Phase Partitioning Mechanisms}

To determine the rate limiting mechanism, a number of researchers have analyzed partitioning behavior from the gas phase to particle surfaces using particle size dependence models based on transport theory (Davison, et.al., 1974; Flagan \& Friedlander, 1976; Biermann and Ondov, 1979; Neville, et. al., 1983; Bool \& Helble, 1995; Helble, 1994; Smith, 1980). For the supermicron particles, it can be shown that (assuming that the particles are spherical in shape and traveling at 

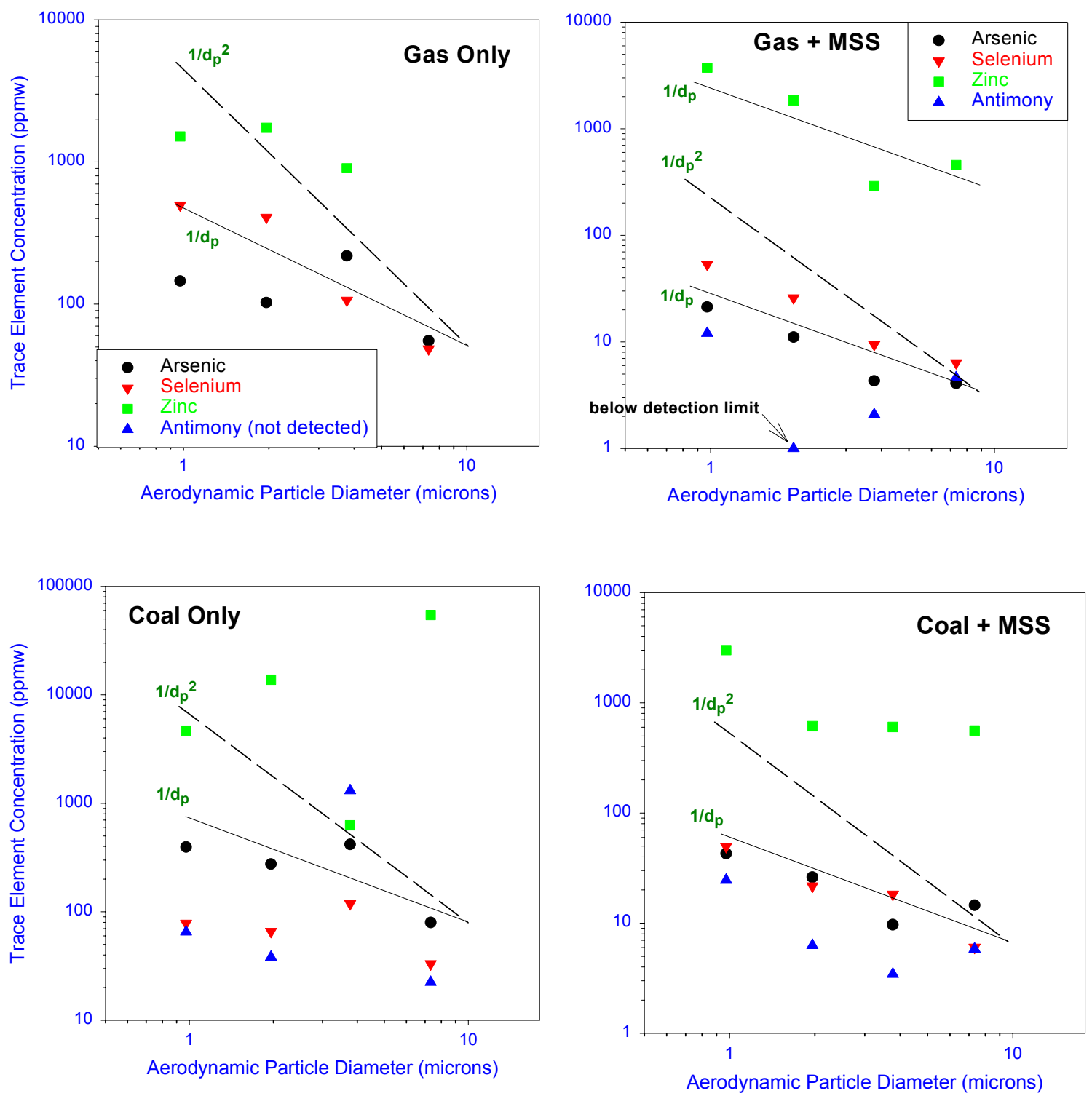

\section{Figure 11. Dependence of trace metal concentration on particle size for super- micron sized particles.}

the same speed as the surrounding gas) transport of a trace element molecule from the vapor phase to the particle surface dominated by gas film transfer will follow an inverse dependence to the square of the particle diameter $\left(1 / \mathrm{D}_{\mathrm{p}}^{2}\right)$. Similarly, if transport is dominated by exterior surface reaction (assuming the particles are non-porous ${ }^{9}$ ), the distribution will follow an inverse dependence to the particle diameter ( $1 / \mathrm{D}_{\mathrm{p}}$; Linak and Wendt, 1994).

The supermicron region particle size dependence for the four trace elements studied at all four test conditions is shown in Figure 11. For the "Gas only" test, there is an apparent particle size dependence for the arsenic and selenium results $\left(1 / \mathrm{D}_{\mathrm{p}}\right)$. However, it should be noted that the total ash mass on these impactor stages is very low and these results may be an artifact of

\footnotetext{
${ }^{9}$ A 1/D dependence may also indicate pore diffusion - controlled transport for porous particles.
} 
gravimetric measurement error ${ }^{10}$ or due to previously deposited particles being swept up by the flus gases.

Dependence $\left(1 / D_{p}\right)$ is indicated for arsenic, selenium, and zinc in the "Gas + MSS" results. This suggests that surface reaction (or pore diffusion in porous particles) controls vapor-to-solid phase partitioning of these trace elements. For Ohio coal only tests, apparent particle size dependence is observed only for arsenic. This result is contrary to previous results for this coal from more extensive testing (Seames, 2000) in which no particle size dependence was observed and may be an artifact of the experiments performed. These results suggest that the vapor-tosolid phase partitioning of these trace elements is not transport controlled.

The "Coal + MSS" results suggest a particle size dependence for arsenic and antimony but not for selenium or zinc (although a possible correlation with selenium is suggested if one data point is ignored). This implies that the partitioning mechanism for As and Sb differs when co-firing MSS with coal than coal alone or MSS combusted with gas assist. As and Sb vapor-to-solid phase partitioning appears to be surface reaction or pore diffusion controlled while $\mathrm{Zn}$ and possibly Se vapor-to-solid phase partitioning does not appear to be transport controlled.

4.2.1 Arsenic Surface Reaction Mechanisms The particle size dependence analysis suggests that surface reaction (or pore diffusion in porous particles) controls vapor-to-solid phase arsenic partitioning. Arsenic volatilized during coal combustion is believed to form an oxy-anion of the form $\mathrm{As}_{2} \mathrm{O}_{3}$ (Huggins, et. al., 1993; Haynes, et. al., 1982) although many thermodynamic studies (Seames, 2000) predict AsO as the primary form at coal combustion conditions. However when formation of $\mathrm{AsO}$ is constrained, oxy-anions (including $\mathrm{As}_{2} \mathrm{O}_{3}$ ) are the predicted forms of occurrence (Seames, 2000; Bool and Helble, 1995). The probability of $\mathrm{As}_{2} \mathrm{O}_{3}$ adherence to a particle's surface is primarily due to the number of active cation sites on the particle surface. $\mathrm{As}_{2} \mathrm{O}_{3}$ will become incorporated into the particle if subsequent reaction between the anion and cation (chemical bonding). The probability that chemical reaction will occur depends upon the rate at which the anion can migrate across the particle surface to the cation site and the kinetic reaction rate between the anion and cation.

To explore the possibility of vapor-phase $\mathrm{As}_{2} \mathrm{O}_{3}$ reaction with cations, the differential distribution of arsenic can be compared to the differential distributions of the cations to see if a correlation exists. This comparison for the "Gas + MSS" and "Coal + MSS" test results are shown in Figure 9. For the "Gas + MSS" profile, the cation distribution curves are very similar. The arsenic distribution appears to follow these profiles reasonably closely in the supermicron region and less closely in the submicron region. For the submicron region, the arsenic distribution most closely resembles the silicon distribution in the submicron region (which implies that vapor-to-solid phase partitioning in this region is not controlled by surface reaction since arsenic is more reactive with active calcium and iron cation surface sites than silicon).

\footnotetext{
${ }^{10}$ A detailed discussion of potential error sources for similar experiments can be found in Appendix B of Seames (2000)
} 

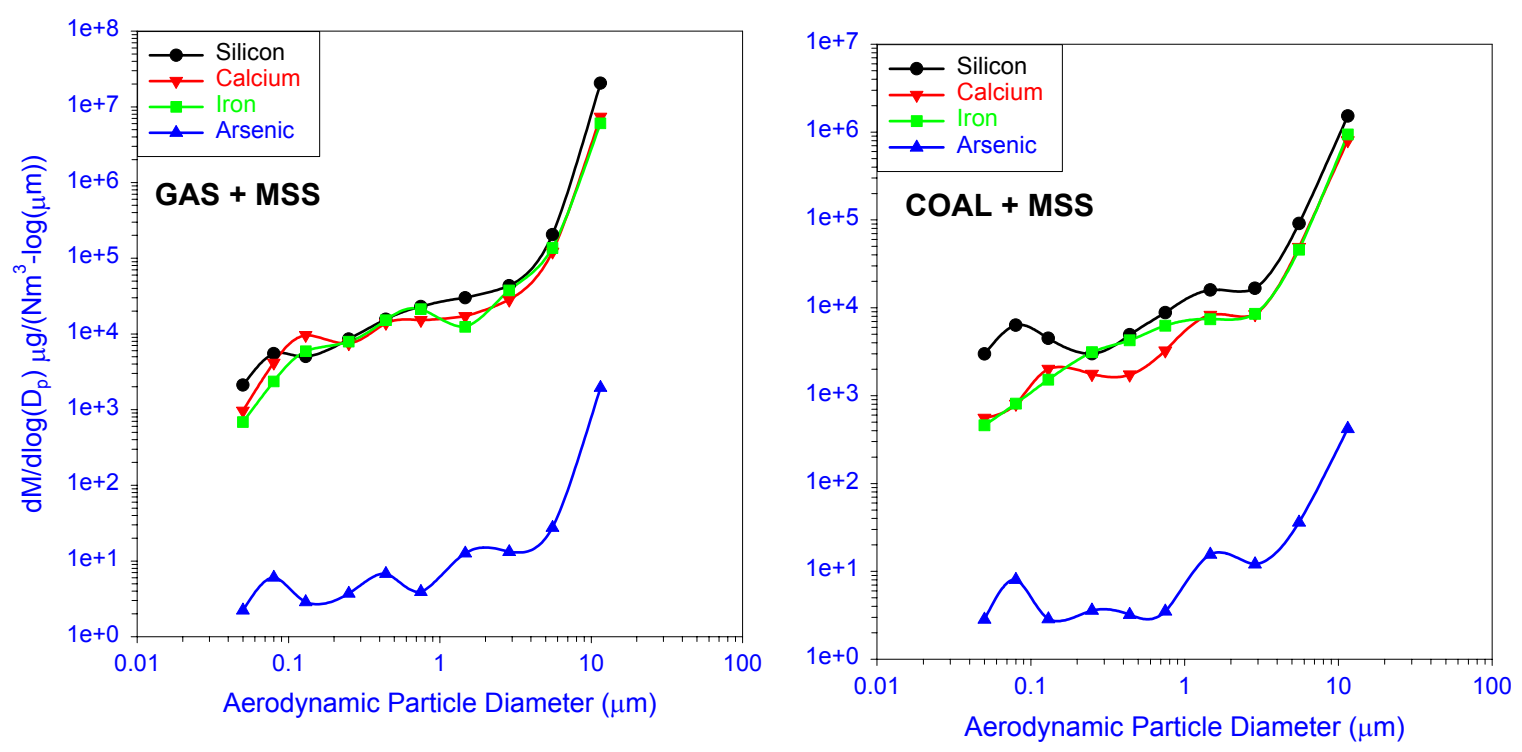

Figure 12. Comparison of arsenic to cation distributions.

For the "Coal + MSS" profile, the cation distribution curves are also similar but there are more discernable differences than with the "Gas + MSS" profiles. Considering the entire profile, the arsenic distribution appears to follow the calcium profile more closely than the silicon and iron profiles.

To examine the results more carefully, the distributions were decomposed into their submicron and supermicron components. Then the correlation between arsenic and calcium/iron was analyzed in two ways. First the cross correlation between the absolute concentration values on each relevant impactor stage was evaluated. Figure 10 shows these correlations for the "Gas + MSS" and "Coal + MSS" cases in the supermicron region. The data suggests a strong correlation of arsenic to calcium and iron in the "Gas + MSS" case (Pearson correlation coefficients, $\left.\mathrm{R}^{2} \sim 1\right)$, a strong correlation of arsenic to iron in the "Coal + MSS" case $\left(\mathrm{R}^{2} \sim 1\right)$, and a fairly good correlation $\left(\mathrm{R}^{2}=0.85\right)$ of arsenic to calcium in the "Coal + MSS" case. These correlations suggest that reaction of vapor phase arsenic with active iron and calcium surface sites is the most likely controlling partitioning mechanism.

For the submicron region, there is no correlation of arsenic to calcium $\left(\mathrm{R}^{2} \sim 0\right)$ and a weak correlation of arsenic to iron $\left(\mathrm{R}^{2}=0.47\right)$ for the "Gas + MSS" case while for the "Coal + MSS" case there is a weak correlation of arsenic to calcium $\left(\mathrm{R}^{2}=0.58\right)$ and no correlation of arsenic to iron $\left(\mathrm{R}^{2} \sim 0\right)$.

A second method of assessing the possible correlation of arsenic to the cations is to evaluate the correlation between the differential distribution curves. This involved fitting a curve through the differential data in the region of interest and then plotting data derived from the arsenic curve versus data derived from the calcium and iron curves (interpolating between the actual discrete data points on the differential distributions). For the supermicron region, two $2^{\text {nd }}$ order polynomials were fit through the five data points. The polynomial through the data from the smaller diameter impactor stages represents the distribution in the near micron-sized 

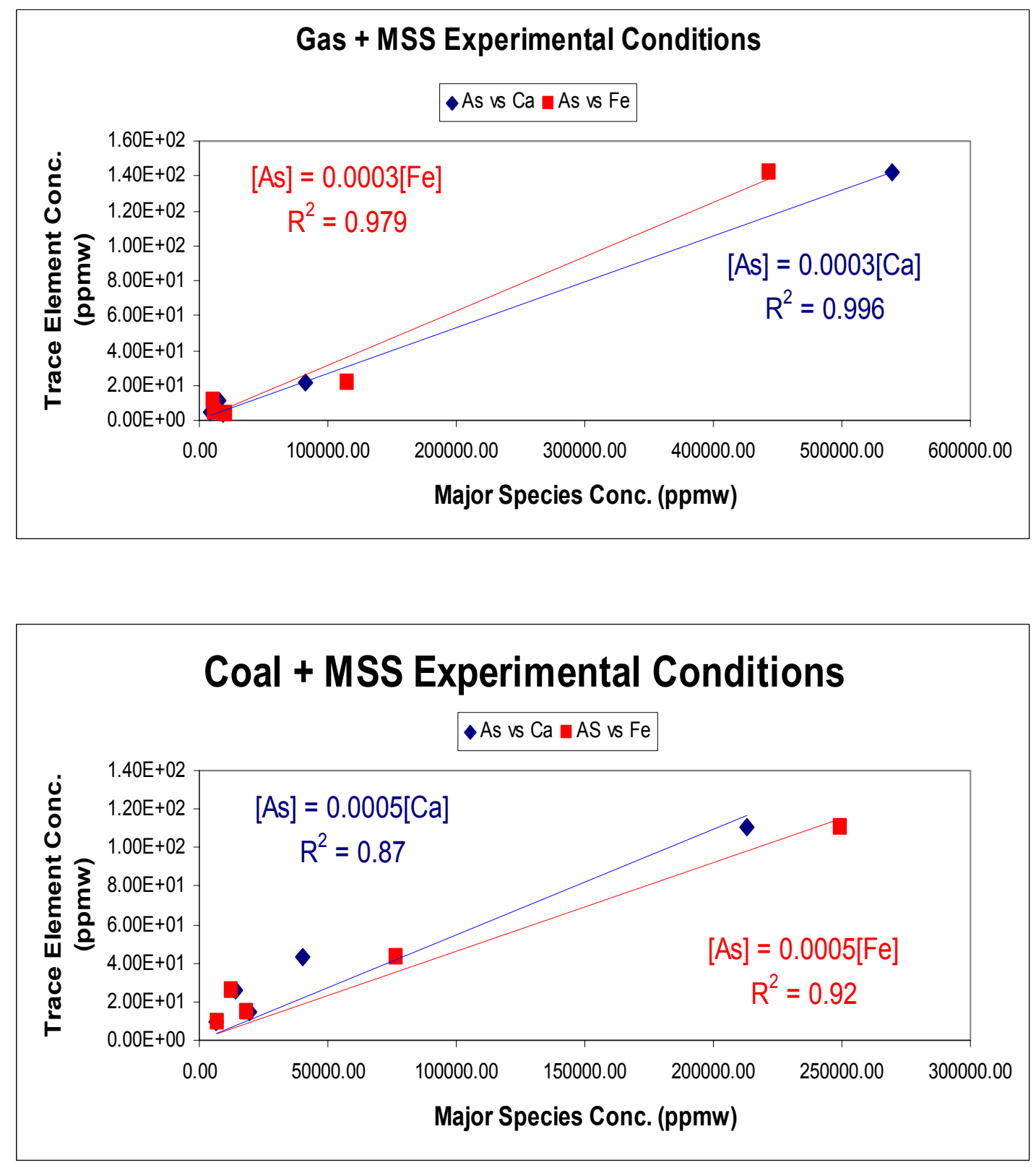

Figure 13. Cross correlation of absolute concentrations of arsenic vs calcium, and arsenic vs iron for super-micron particles.

fragmentation region while the data from the larger diameter impactor stages represents the distribution in the larger, bulk fly ash. Curves for the supermicron region for the "Gas + MSS" experiments are shown in Fig 14. The overall correlation in the supermicron region is strong for arsenic vs. both calcium and iron $\left(\mathrm{R}^{2}=0.93\right)$. These results are consistent with the absolute correlation results described above. For the submicron region, a strong correlation was found for arsenic with both calcium and iron $\left(\mathrm{R}^{2} \sim 1\right)$ from the differential distribution analysis whereas the absolute value correlation found only weak correlation. The differences in these results are most likely due to the increased variation in absolute data from submicron impactor stage analysis. These stages typically have mass loadings an order of magnitude lower $(\varnothing[0.001 \mu \mathrm{g}]$ 

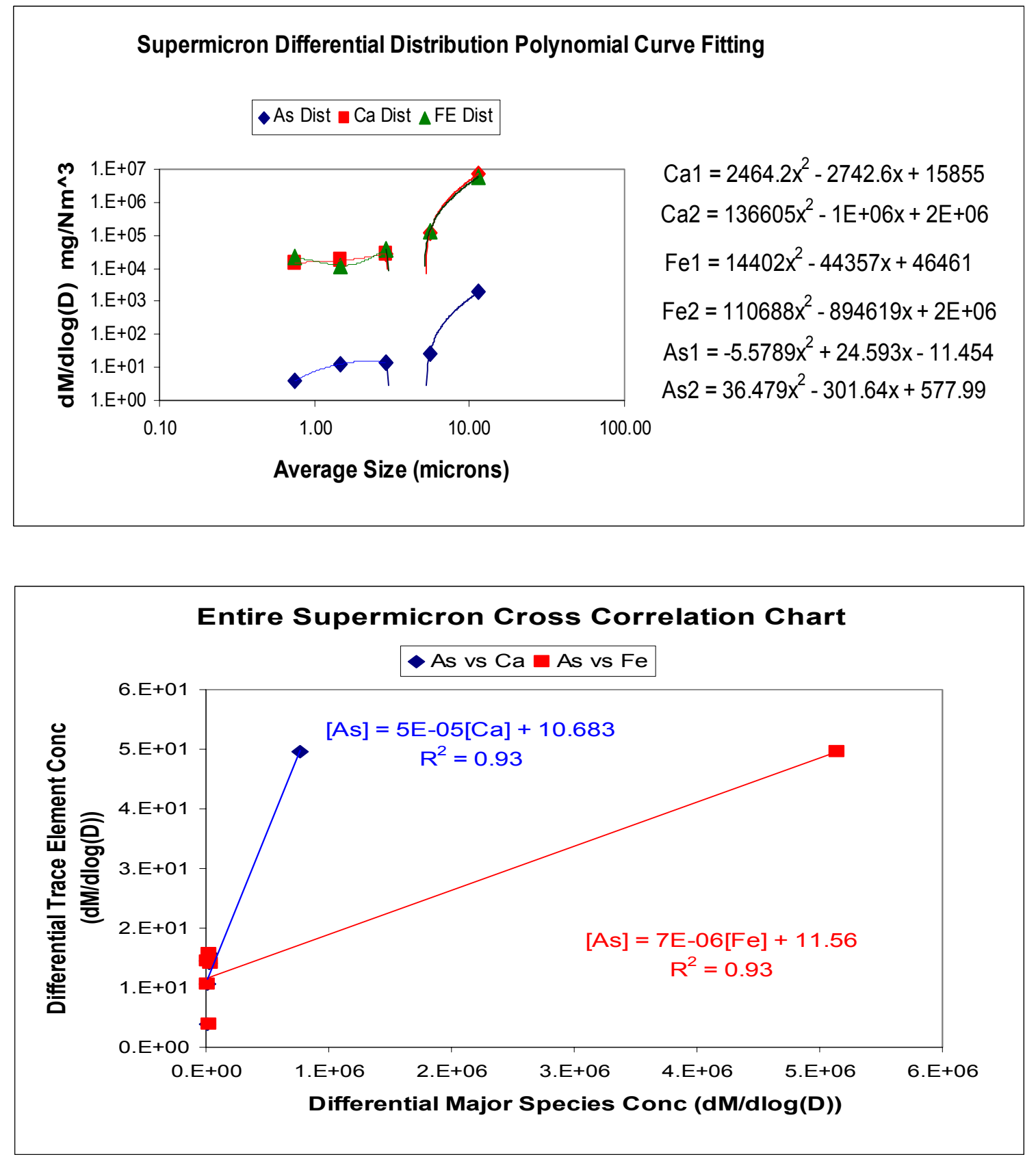

Figure 14. MSS with gas assist. Cross correlation of differential elemental distributions, As vs Ca and As vs Fe in supermicron region. Upper panel: curve fits for differential distributions. Lower panel: final cross correlations.

vs. $\varnothing[0.01 \mu \mathrm{g}])$. Therefore, gravimetric and analytical error imparts greater variability in the results from submicron stages than from supermicron stages ${ }^{11}$. Thus, the differential correlation results are more likely to be indicative of correlation than the absolute value correlation in the submicron region. In both regions the results suggest that vapor-to-solid phase arsenic

${ }^{11}$ A detailed discussion of data quality for similar experiments can be found in Appendix B of Seames(2000). 

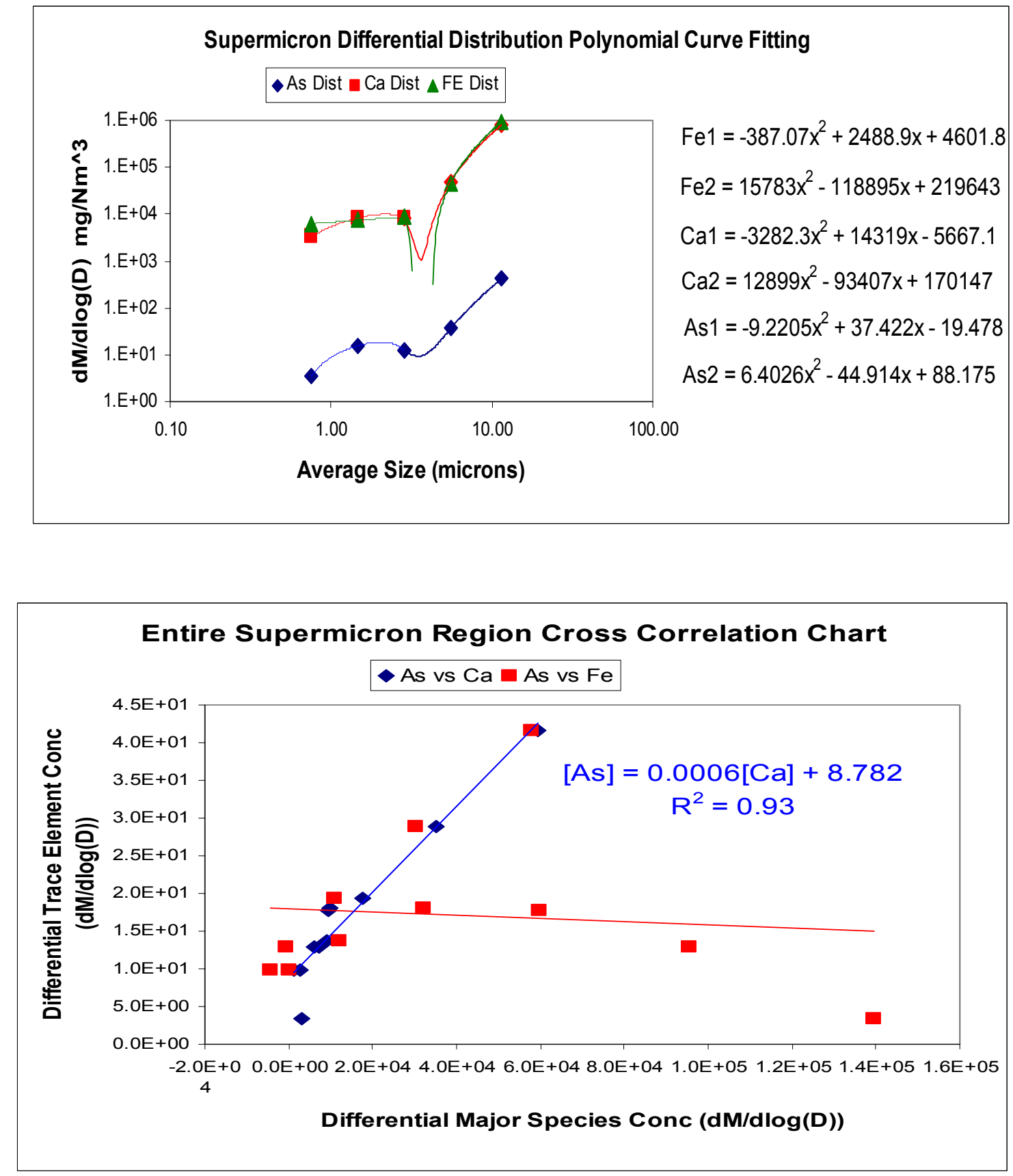

Figure 15. MSS+Coal. Cross correlation of differential elemental distributions. As vs $\mathrm{Ca}$ and $\mathrm{As}$ vs $\mathrm{Fe}$ in supermicron region. Upper panel: curve fits; lower panel: final cross correlations.

partitioning during MSS combustion with gas assist is controlled by surface reaction with calcium and iron surface sites.

The differential correlation curves for arsenic vs. calcium and iron from the "Coal + MSS" results are shown in Fig 15. Taking the entire supermicron region shown in lower panel of Fig. 15 , arsenic correlates strongly with calcium $\left(\mathrm{R}^{2}=0.93\right)$ but not with iron $\left(\mathrm{R}^{2} \sim 0\right)$. However the 

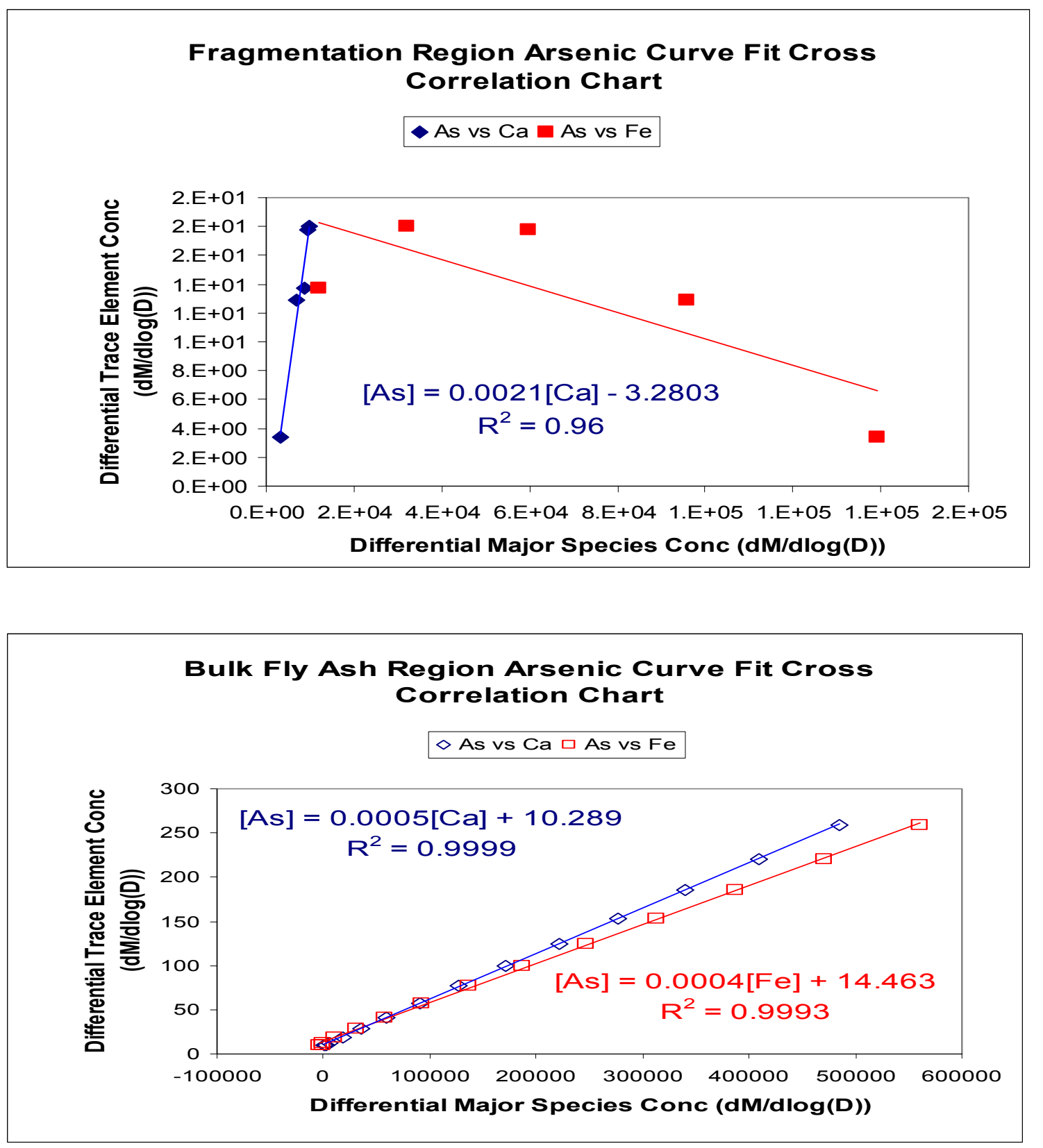

Figure 16. Additional cross-correlation details. Cross correlation curves for fragmentation region (upper panel) and bulk fly ash region (lower panel).

"Coal + MSS" PSD in Fig 10 suggests that the supermicron particle distribution is comprised of two regions: a micron-sized fragmentation region (Fig. 16, upper panel) and a bulk ( $>3 \mu \mathrm{m}$ diameter) bulk fly ash region (Fig. 16, lower panel). The fragmentation region results are consistent with the results for the entire supermicron region. However in the bulk fly ash region, arsenic appears to correlate strongly with both calcium and iron. These results suggest that arsenic partitioning in the fragmentation region is controlled by surface reaction with calcium but in the bulk fly ash region reaction with calcium and/or iron surface sites are suggested. 
For the submicron region, arsenic does not appear to correlate with either calcium or iron $\left(\mathrm{R}^{2} \sim\right.$ $0)$.

Previous research (Seames, 2000) has shown that arsenic does not correlate with either calcium or iron during the combustion of the Ohio coal alone. The apparent correlation of arsenic with calcium in the "Coal + MSS" results in supermicron particles but not in submicron particles suggests that calcium from MSS surface sites are available in the fragmentation size range. However the fragmentation mode in the "Coal + MSS" PSD shown in Fig. 7 is less pronounced than for the "Coal only" PSD suggesting that only the coal is participating in the fragmentation mechanism. Thus, the availability of calcium from MSS surface sites in this size range is most probably comparable to the availability in the bulk fly ash size range. What is more revealing is the apparent lack of correlation with iron in the fragmentation region when the bulk fly ash region results suggest correlation. Two possible explanations are 1) arsenic is not actually reacting with iron but the similarity of the iron distribution to the calcium distribution results in an apparent correlation or 2) sulfur preferentially ties up iron surface sites in fragmentation sized-particles compared to bulk fly ash particles ${ }^{12}$. The first of these alternatives is more likely since there is no apparent reason for preferential reactivity of sulfur with fragmentation iron surface sites.

To summarize, a detailed analysis of arsenic vapor-to-solid phase partitioning suggests that arsenic reaction with calcium and iron surface sites is the controlling mechanism for MSS combustion with gas assist. For co-firing of Ohio coal with MSS, arsenic vapor-to-solid phase partitioning is controlled by the reaction of arsenic with calcium in the supermicron region (due to active MSS-originating surface sites) but not in the submicron region.

4.2.2 Antimony Surface Reaction Mechanisms The particle size dependence analysis suggests that surface reaction (or pore diffusion in porous particles) controls vapor-to-solid phase antimony partitioning. Due to the similarity in chemistry with arsenic, vapor phase antimony volatilized during coal combustion is believed to form an oxy-anion of the form $\mathrm{Sb}_{2} \mathrm{O}_{3}$ although thermodynamic studies (Seames, 2000) predict $\mathrm{SbO}$ as a major specie. The probability of $\mathrm{Sb}_{2} \mathrm{O}_{3}$ adherence to a particle's surface is primarily due to the number of active cation sites on the particle surface. $\mathrm{Sb}_{2} \mathrm{O}_{3}$ will become incorporated into the particle if subsequent reaction between the anion and cation (chemical bonding) occurs. The probability that chemical reaction will occur depends upon the rate at which the anion can migrate across the particle surface to the cation site and the kinetic reaction rate between the anion and cation.

To explore the possibility of vapor-phase $\mathrm{Sb}_{2} \mathrm{O}_{3}$ reaction with cations, the differential distribution of antimony can be compared to the differential distributions of the cations to see if a correlation exists. This comparison for the "Gas + MSS" and "Coal + MSS" test results are shown in Figure 17. For the "Gas + MSS" profile, the antimony distribution appears to follow the iron and aluminum curves reasonably closely in the supermicron region and the calcium curve in the submicron region. While in the "Coal + MSS" profile, the antimony distribution appears to follow the silicon and calcium distributions in both regions.

\footnotetext{
${ }^{12}$ Previous research has shown that sulfur inhibits the reaction of arsenic with iron in high sulfur coals (Seames, 2000).
} 
To examine the results more carefully, the distributions were decomposed into their submicron
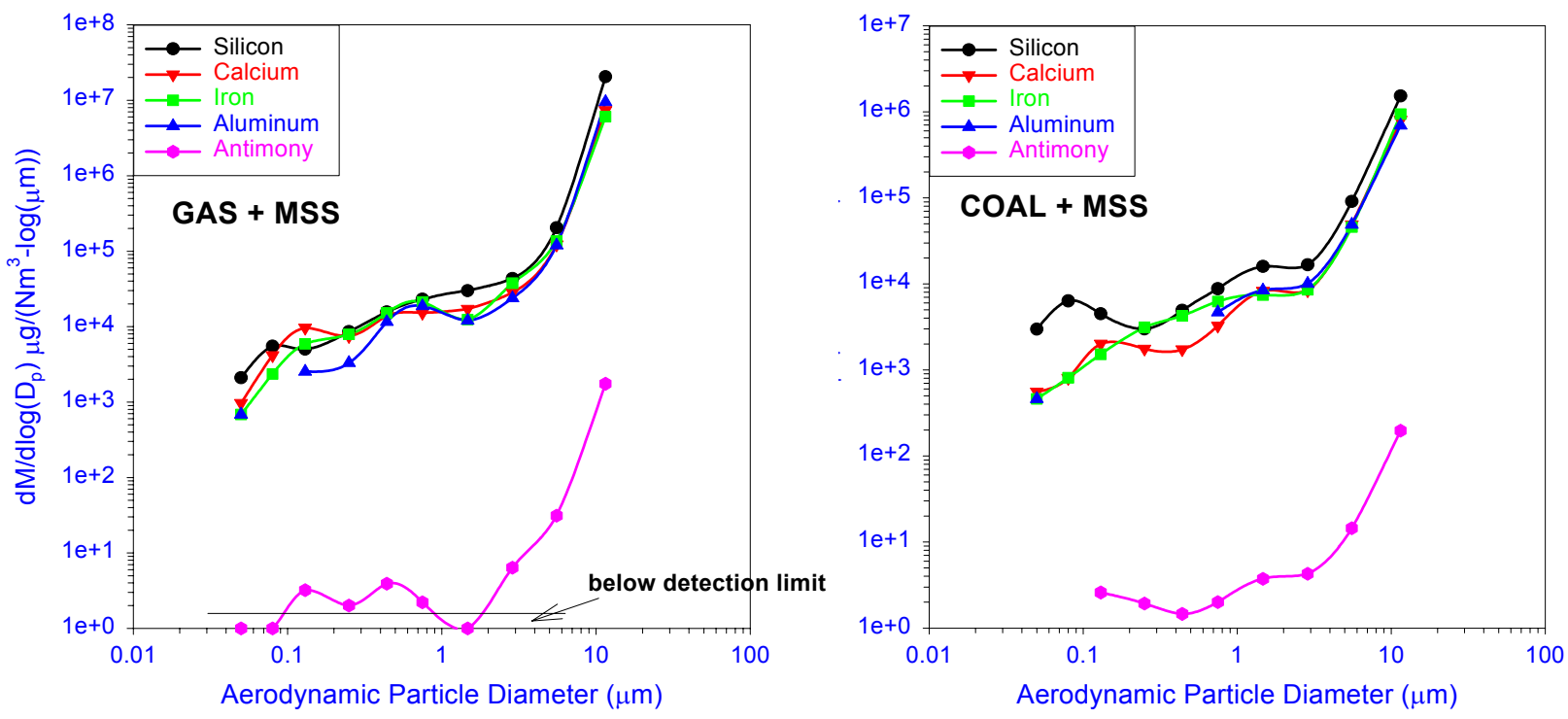

Figure 17. Antimony. Comparison to major element distributions.

and supermicron components. Then the correlation between antimony and calcium/iron was analyzed in the two ways described above for arsenic. The correlation results are summarized in Table 5. The data suggests a strong correlation of antimony to calcium, iron, and aluminum in the "Gas + MSS" case submicron region (Pearson correlation coefficients, $\mathrm{R}^{2} \sim 1$ ). In the supermicron region, there is a strong correlation of antimony to all three major elements in the bulk fly ash region. In the fragmentation region the correlation is strongest with iron $\left(\mathrm{R}^{2} \sim 1\right)$, then with aluminum $\left(R^{2}=0.88\right)$, and weakest with calcium $\left(R^{2}=0.58\right)$. These correlations make identification of a reaction mechanism difficult. Most likely, the three major element distributions are just too similar to discern the correct reaction mechanism. However it is also possible that vapor-phase antimony is reacting with both cations and anions on the particle surface. The formation of AlSb is a predicted form of occurrence in many cases of coal combustion (Seames, 2000). The size of the antimony molecule (it has an additional electron shell compared to As and Se) makes multiple valence states more likely than the arsenic or selenium molecules. In this respect, antimony acts more like a metal than arsenic (Norman, 1998).

The "Coal + MSS" results indicate a correlation of antimony with calcium in the submicron region but not with iron or aluminum. Strong correlation of antimony with all three major elements is indicated in the bulk fly ash region $\left(\mathrm{R}^{2} \sim 1\right)$. In the fragmentation region, strong correlation is calculated with antimony for calcium and aluminum $\left(\mathrm{R}^{2} \sim 1\right)$ but no correlation is suggested for antimony with iron $\left(\mathrm{R}^{2} \sim 0\right)$.

Previous research (Seames, 2000) has shown that antimony does not correlate with calcium, iron, or aluminum during the combustion of the Ohio coal alone. The apparent strong correlation of 
Table 5

Correlation Coefficients for Antimony vs. Calcium, Iron, and Aluminum

in Fly Ash Particles from the MSS Experiments

\begin{tabular}{|c|c|c|c|c|c|c|}
\hline & $\begin{array}{l}\text { Submicron } \\
\text { Correlations } \\
\end{array}$ & & $\begin{array}{l}\text { Supermicron } \\
\text { Correlations } \\
\end{array}$ & & & \\
\hline Coal & $\begin{array}{l}\text { Absolute } \\
\text { Concentrations }\end{array}$ & $\begin{array}{l}\text { Differential } \\
\text { Distributions }\end{array}$ & $\begin{array}{l}\text { Overall } \\
\text { Absolute } \\
\text { Concentrations }\end{array}$ & $\begin{array}{l}\text { Overall } \\
\text { Differential } \\
\text { Distributions }\end{array}$ & $\begin{array}{l}\text { Fragmentation } \\
\text { Region } \\
\text { Differential } \\
\text { Distributions } \\
\end{array}$ & $\begin{array}{l}\text { Bulk Fly Ash } \\
\text { Region } \\
\text { Differential } \\
\text { Distributions }\end{array}$ \\
\hline $\begin{array}{l}\text { Gas }+ \text { MSS: } \\
\text { Sb vs. Ca }\end{array}$ & 0.90 & 0.98 & 0.99 & 0.71 & 0.58 & $\sim 1$ \\
\hline Sb vs. Fe & $\sim 0$ & $\sim 1$ & 0.96 & 0.55 & 1.0 & 0.99 \\
\hline Sb vs. Al & $\sim 0$ & $\sim 1$ & 1.0 & 0.78 & 0.88 & $\sim 1$ \\
\hline $\begin{array}{l}\text { Coal + MSS: } \\
\text { Sb vs. Ca }\end{array}$ & 0.49 & 0.75 & 0.87 & $\sim 1$ & 0.98 & $\sim 1$ \\
\hline Sb vs. Fe & $\sim 0$ & $\sim 0$ & 0.95 & $\sim 0$ & $\sim 0$ & $\sim 1$ \\
\hline Sb vs. Al & nd13 & na & 0.96 & $\sim 1$ & $\sim 1$ & $\sim 1$ \\
\hline
\end{tabular}

${ }^{13} \mathrm{nd}=$ aluminum concentrations below analytical detection limit 
antimony with major elements in the "Coal + MSS" results in supermicron particles but only weakly in submicron particles suggests that active surface sites from MSS are available in the fragmentation size range. However the fragmentation mode in the "Coal + MSS" PSD shown in Fig. 7 is less pronounced than for the "Coal only" PSD suggesting that only the coal is participating in the fragmentation mechanism. Thus, the availability of calcium and possibly aluminum from MSS surface sites in this size range is most probably comparable to the availability in the bulk fly ash size range. What is more revealing is the apparent lack of correlation with iron in the fragmentation region when the bulk fly ash region results suggest correlation. Most probably antimony is not actually reacting with iron but the similarity of the iron distribution to the calcium distribution results in an apparent correlation ${ }^{14}$.

4.2.3 Selenium Surface Reaction Mechanisms The particle size dependence analysis is unclear concerning whether vapor-to-solid phase selenium partitioning is transport controlled during MSS combustion. Based on the similarity of selenium partitioning during coal combustion to arsenic (Seames, 2000), it is probable that selenium is reacting with active surface sites during MSS combustion. Bool and Helble (1995) have proposed a reaction of $\mathrm{SeO}_{2}$ with iron cations or calcium cations as the most likely partitioning mechanisms, depending upon the coal composition. Work with other oxy-anions (e.g. arsenic) and the success of lime sorbents to remove Se and $\mathrm{SO}_{2}$ (Gullett and Ragnunanthan, 1994; Agnihotri, et. al., 1998), reinforce this hypothesis.

To explore the possibility of vapor-phase $\mathrm{SeO}_{2}$ reaction with cations, the differential distribution of selenium can be compared to the differential distributions of the cations to see if a correlation exists. This comparison for the "Gas + MSS" and "Coal + MSS" test results are shown in Fig 18. Particle size dependence analysis indicated that vapor-to-solid phase selenium partitioning was surface reaction controlled in the natural gas only test. It was suggested that this apparent dependence was an artifact of the measurement process. The results in Fig. 18a support this hypothesis. There is clearly no relationship between selenium and the major cations during "Gas only" combustion.

For the "Gas + MSS" profile, the cation distribution curves are very similar. The selenium distribution appears to follow these profiles reasonably closely in both supermicron and submicron regions. In the "Coal + MSS" profile, selenium still appears to follow the cation distributions but not as closely as in the "Gas + MSS' profile. Specifically, fragmentation region selenium appears to follow the calcium distribution much more closely than the iron distribution.

To examine the results more carefully, the distributions were decomposed into their submicron and supermicron components. Then the correlation between selenium and calcium/iron was analyzed in the two ways described above for arsenic. The correlation results are summarized in Table 6. The data suggests a strong correlation of selenium with calcium and iron in the submicron and bulk fly ash regions $\left(\mathrm{R}^{2} \sim 1\right)$, a weaker correlation of selenium with calcium in

\footnotetext{
${ }^{14}$ Previous research has shown that sulfur does not inhibit the reaction of antimony with iron in high sulfur coals (Seames, 2000) in contrast to arsenic and selenium.
} 

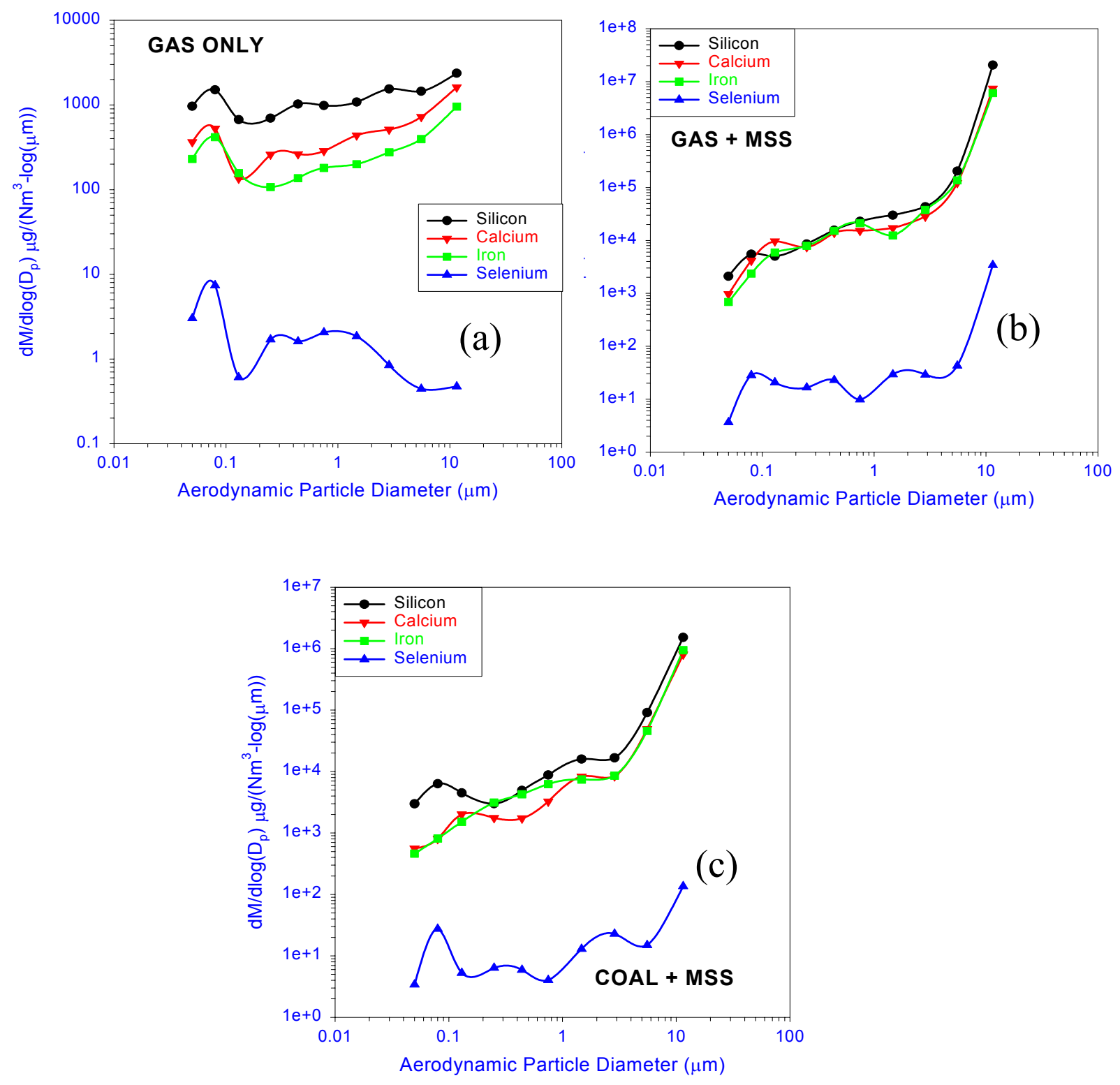

Figure 18. Comparison of Selenium to cation distributions.

the fragmentation region $\left(\mathrm{R}^{2}=0.41\right)$, and no correlation of selenium with iron in the fragmentation region $\left(\mathrm{R}^{2} \sim 0\right)$ for the "Gas + MSS" test conditions. These results suggest selenium vapor-to-solid phase partitioning is controlled by surface reaction with calcium and possibly with iron ${ }^{15}$.

\footnotetext{
${ }^{15}$ The apparent correlation with iron in the submicron and fragmentation regions could be due to the similarity of the iron and calcium distributions.
} 
Table 6

Correlation Coefficients for Selenium vs. Calcium and Iron in Fly Ash Particles from the MSS Experiments

\begin{tabular}{|l|c|c|c|c|c|c|}
\hline & \multicolumn{2}{|c|}{ Submicron Correlations } & \multicolumn{2}{c|}{} & \\
\hline Coal & $\begin{array}{c}\text { Absolute } \\
\text { Concentrations }\end{array}$ & $\begin{array}{c}\text { Differential } \\
\text { Distributions }\end{array}$ & $\begin{array}{c}\text { Overall Absolute } \\
\text { Concentrations }\end{array}$ & $\begin{array}{c}\text { Fragmentation } \\
\text { Overall } \\
\text { Differential } \\
\text { Distributions } \\
\text { Differential } \\
\text { Distributions }\end{array}$ & $\begin{array}{c}\text { Bulk Fly Ash } \\
\text { Region } \\
\text { Differential } \\
\text { Distributions }\end{array}$ \\
\hline Gas + MSS: & 0.83 & $\sim 1$ & 0.99 & 0.86 & 0.41 & $\sim 1$ \\
SE VS. CA & $\sim 0$ & 0.98 & 0.99 & 0.85 & $\sim 0$ & 0.99 \\
Se vs. Fe & 0.63 & $\sim 0$ & $\sim 0$ & $\sim 0$ & 0.82 & $\sim 1$ \\
\hline COAL + MSS: & $\sim 0$ & $\sim 0$ & $\sim 0$ & 0.56 & $\sim 0$ & $\sim 1$ \\
Se vs. Ca & & & & \\
Se vs. Fe & & & & & \\
\hline
\end{tabular}


For the "Coal + MSS" profile, there is no apparent correlation of selenium with either cation in the submicron region $\left(\mathrm{R}^{2} \sim 0\right)$, strong correlation with both cations in the bulk fly ash region $\left(\mathrm{R}^{2} \sim 1\right)$, strong correlation with calcium in the fragmentation region $\left(\mathrm{R}^{2}-0.82\right)$, and no correlation with iron in the fragmentation region $\left(\mathrm{R}^{2} \sim 0\right)$. These results suggest selenium vapor-to-solid phase partitioning is controlled by surface reaction with calcium. Previous research (Seames, 2000) has shown that selenium does not correlate with calcium or iron during the combustion of the Ohio coal alone. The apparent strong correlation of selenium with calcium in the "Coal + MSS" results in the supermicron particle region but not in the submicron region suggests that active surface sites from MSS are available in the fragmentation size range. However the fragmentation mode in the "Coal + MSS" PSD shown in Fig. 4 is less pronounced than for the "Coal only" PSD suggesting that only the coal is participating in the fragmentation mechanism. Thus, the availability of calcium from MSS surface sites in this size range is most probably comparable to the availability in the bulk fly ash size range. What is more revealing is the apparent lack of correlation with iron in the fragmentation region when the bulk fly ash region results suggest correlation. Previous research (Seames, 2000) has shown that selenium is more reactive with iron than calcium surface sites during coal combustion. Most probably selenium is not actually reacting with iron but the similarity of the iron distribution to the calcium distribution results in an apparent correlation.

4.2.4 Zinc Surface Reaction Mechanisms The particle size dependence analysis suggests that vapor-to-solid phase zinc partitioning is transport controlled during "Gas + MSS" combustion but not during "Coal + MSS" combustion. Zinc is a Group 2b transition metal (located just above cadmium on the periodic table). Previous research (Seames and Wendt, 2000) has shown that cadmium correlates with calcium during certain coal combustion conditions. However other transition metals (e.g. cobalt) have been shown (Seames, 2000) to correlate with both cations and anions during coal combustion. A comparison of the zinc differential distribution to major elements for the "Gas + MSS" and "Coal + MSS" experiments is shown in Figure 19. For both
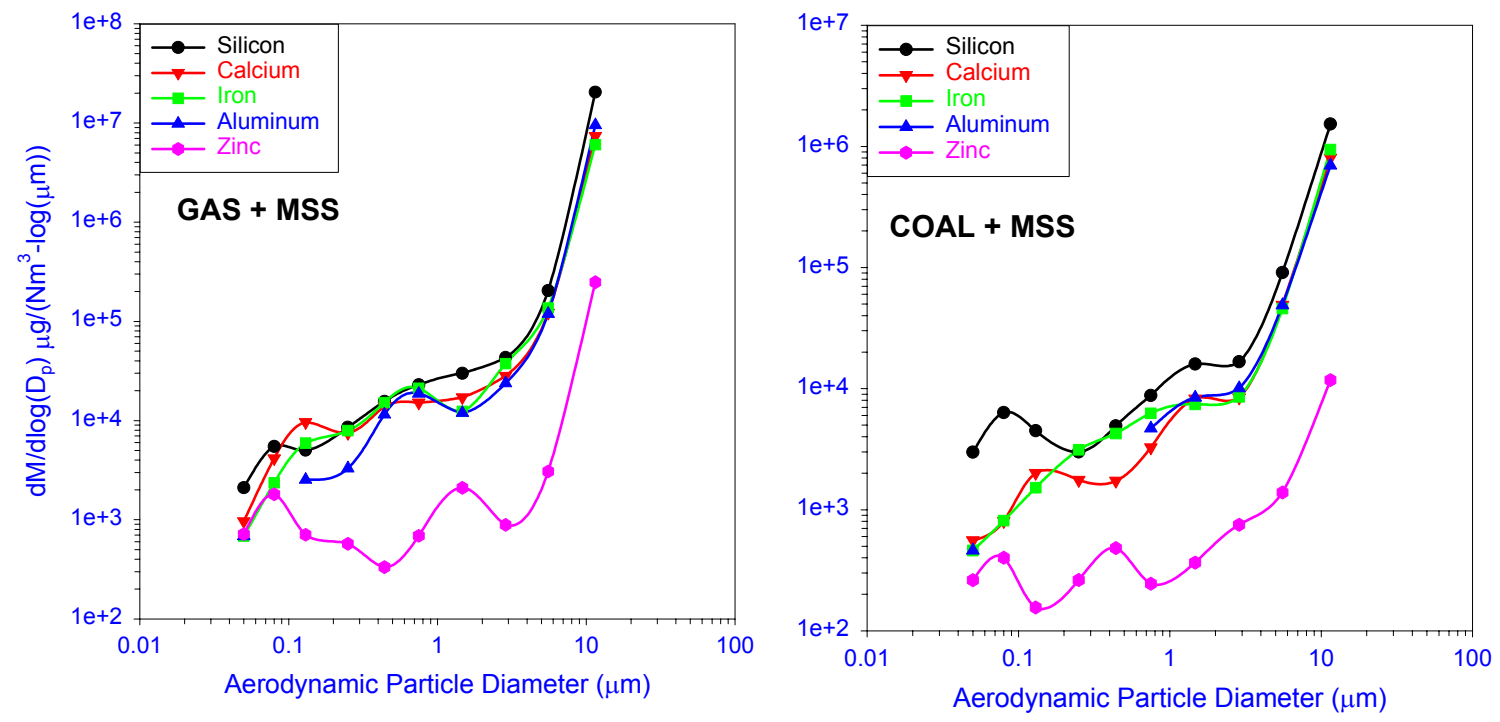

Figure 19. Comparison of Zinc to major elements distributions. 
cases, the zinc distribution appears to following the major element distributions in the bulk fly ash region only. Cross correlation data for zinc vs. calcium, iron, and aluminum are shown in Table 7. For the "Gas + MSS" conditions, there is a strong correlation to all three major elements in the bulk region but no apparent correlation in the submicron or fragmentation regions. This suggests that partitioning of volatilized zinc to particle surfaces is not surface reaction controlled and thus probably not a transport controlled process.

In the "Coal + MSS" data, correlation is suggested for zinc with calcium in the submicron $\left(\mathrm{R}^{2}=\right.$ $0.84)$, fragmentation $\left(\mathrm{R}^{2}=0.76\right)$, and bulk regions $\left(\mathrm{R}^{2} \sim 1\right)$. Correlation with aluminum is suggested in the fragmentation $\left(\mathrm{R}^{2}=0.76\right)$ and bulk fly ash regions $\left(\mathrm{R}^{2} \sim 1\right)$ while correlation with iron is indicated only in the bulk fly ash region $\left(\mathrm{R}^{2} \sim 1\right)$. Recall though that no particle size dependence was observed in the "Coal + MSS" zinc data and that all of the major element distributions are very similar in shape. Taken together, the results suggest that like all of the trace elements studied, zinc follows the major elements in the bulk fly ash. However, vapor-tosolid phase zinc partitioning to submicron and fragmentation particles is probably not transport controlled.

\subsection{Health Effects Engineering Studies}
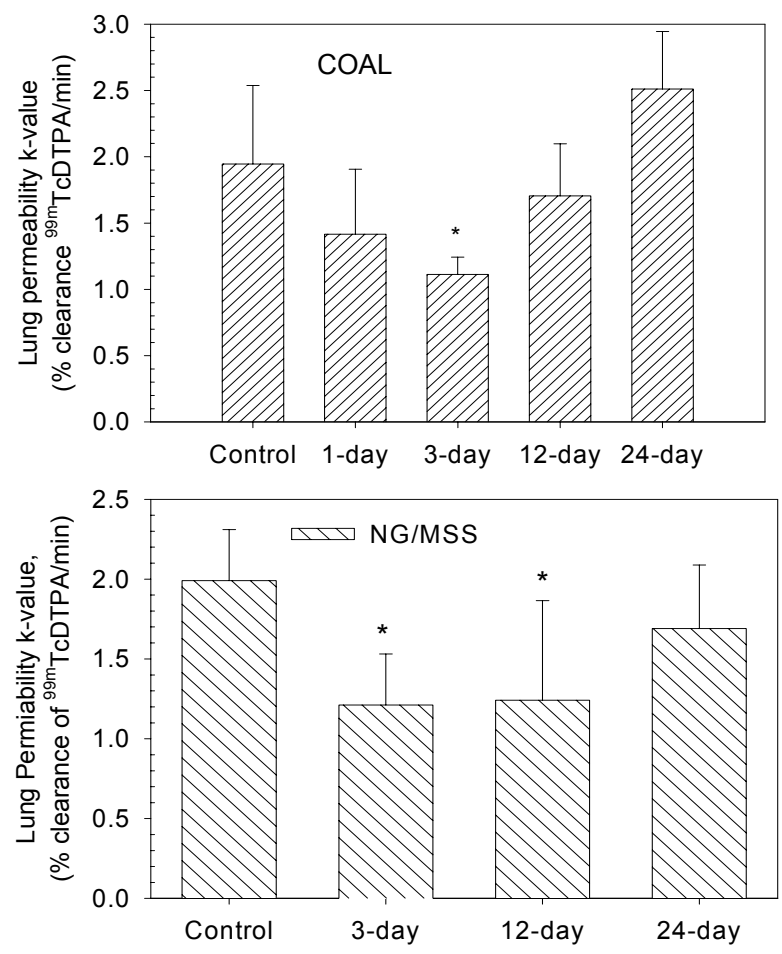

Figure 20. Lung permeability due to inhaled coal ash (upper) and MSS ash (lower). Temporal progression of lung permeability for exposures of 1 hour each day for 1, 3, 12, and 24 days. 
Table 7

Correlation Coefficients for Zinc vs. Calcium, Iron, and Aluminum

in Fly Ash Particles from the MSS Experiments

\begin{tabular}{|c|c|c|c|c|c|c|}
\hline \multirow[b]{2}{*}{ Coal } & \multicolumn{2}{|c|}{ Submicron Correlations } & \multirow[b]{2}{*}{$\begin{array}{l}\text { Overall } \\
\text { Absolute } \\
\text { Concentrations }\end{array}$} & \multicolumn{2}{|c|}{ Supermicron Correlations } & \multirow[b]{2}{*}{$\begin{array}{l}\text { Bulk Fly Ash } \\
\text { Region } \\
\text { Differential } \\
\text { Distributions } \\
\end{array}$} \\
\hline & $\begin{array}{l}\text { Absolute } \\
\text { Concentrations }\end{array}$ & $\begin{array}{l}\text { Differential } \\
\text { Distributions }\end{array}$ & & $\begin{array}{l}\text { Overall } \\
\text { Differential } \\
\text { Distributions } \\
\end{array}$ & $\begin{array}{l}\text { Fragmentation } \\
\text { Region } \\
\text { Differential } \\
\text { Distributions } \\
\end{array}$ & \\
\hline $\begin{array}{l}\text { Gas + MSS: } \\
\text { Zn vs. Ca }\end{array}$ & 0.45 & $\sim 0$ & 0.99 & 0.90 & $\sim 0$ & $\sim 1$ \\
\hline Zn vs. Fe & $\sim 0$ & $\sim 0$ & 0.99 & 0.90 & $\sim 0$ & $\sim 1$ \\
\hline Zn vs. Al & $\sim 0$ & $\sim 0$ & 0.98 & 0.90 & $\sim 0$ & 0.99 \\
\hline $\begin{array}{l}\text { Coal + MSS: } \\
\text { Zn vs. Ca }\end{array}$ & 0.30 & 0.84 & 0.16 & 0.76 & 0.56 & $\sim 1$ \\
\hline $\mathrm{Zn}$ vs. Fe & 0.97 & $\sim 0$ & 0.40 & $\sim 0$ & $\sim 0$ & $\sim 1$ \\
\hline Zn vs. Al & $\mathrm{nd}^{16}$ & na & 0.44 & 0.82 & 0.76 & $\sim 1$ \\
\hline
\end{tabular}

${ }^{16} \mathrm{nd}=$ aluminum concentrations below analytical detection limit 
4.3.1 Coal Only and MSS Only (with Gas Assist). Potential lung injury is often preceded by increases in lung permeability. Decreases in permeability, however, are not necessarily benign, since they can indicate consequences of severe inflammation.

Fig 20 shows permeability results, as measured by the rate at which DTPA is removed from the lungs of mice that were exposed, relative to the control. Inhaled ash from coal, and inhaled ash from MSS alone behave similarly. There was a decrease of lung permeability followed by a recovery and return to control values. A decrease in permeability could occur after only a single exposure, as seen from the upper panel of Fig 20. This is very different from the consequences of inhaling ash from the co-combustion of coal and MSS, shown on Fig. 1. However, the coal only results are consistent with each other, at the 24 day exposure time period. Furthermore, both the coal data and the MSS data are similar to data from inhalation of residual oils fly ash (ROFA) and many other types of combustion generated particles. They show a decrease in permeability followed by a recovery. This is in contrast to ash from the co-combustion of coal and MSS, which showed a significant net increase after 24 days, compared to both the control, and to the ash from coal alone.

4.3.2 Doped distillate oil: zinc only and zinc plus sulfur . In order to generate zinc particles, doped distilled fuel oil was combusted in a cylindrical laboratory downflow combustor. The doping agents were zinc naphthenate and zinc naphthenate plus thiophene, in order to achieve a $100 \mathrm{ppm}$ of both zinc and sulfur in the reactor's flue gas. Particles were collected from a cyclone train (In-Tox, Albuquerque; NM) and a custom made filter system. The cyclone train consisted of two cyclones. The first cyclone was designed to remove particles larger then $10 \mu \mathrm{m}$ in diameter while cyclone two was designed to remove particles larger than $2 \mu \mathrm{m}$. The custom-

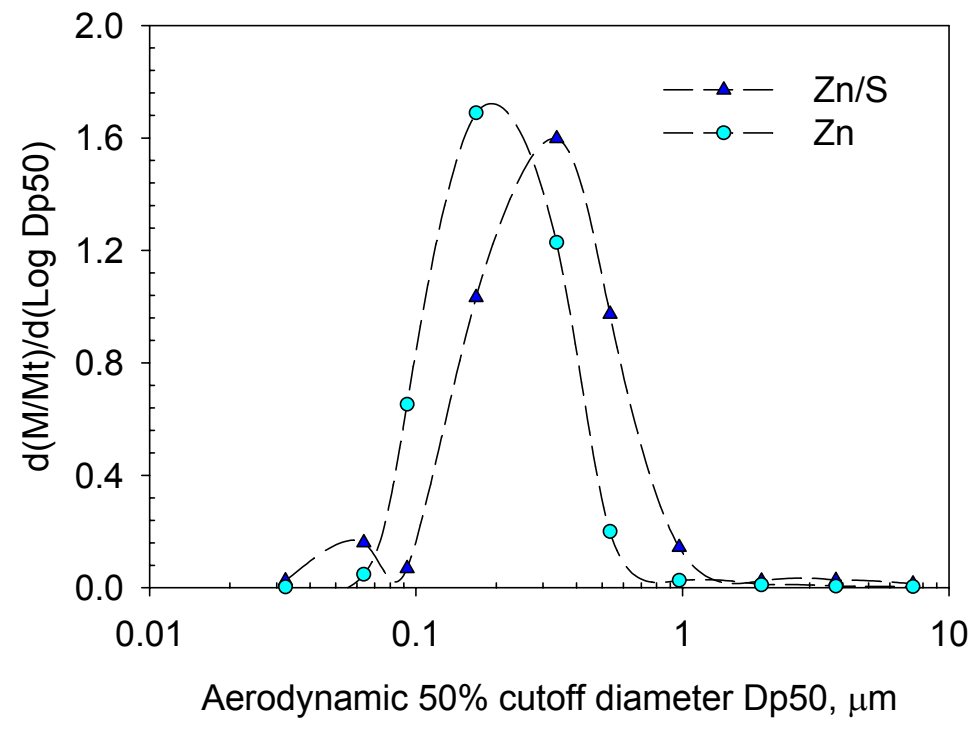

Figure 21 Particle size distributions of sampled particles from combustion of distillate oil with a) $\mathrm{Zn}$ only b) $Z n+S$. 


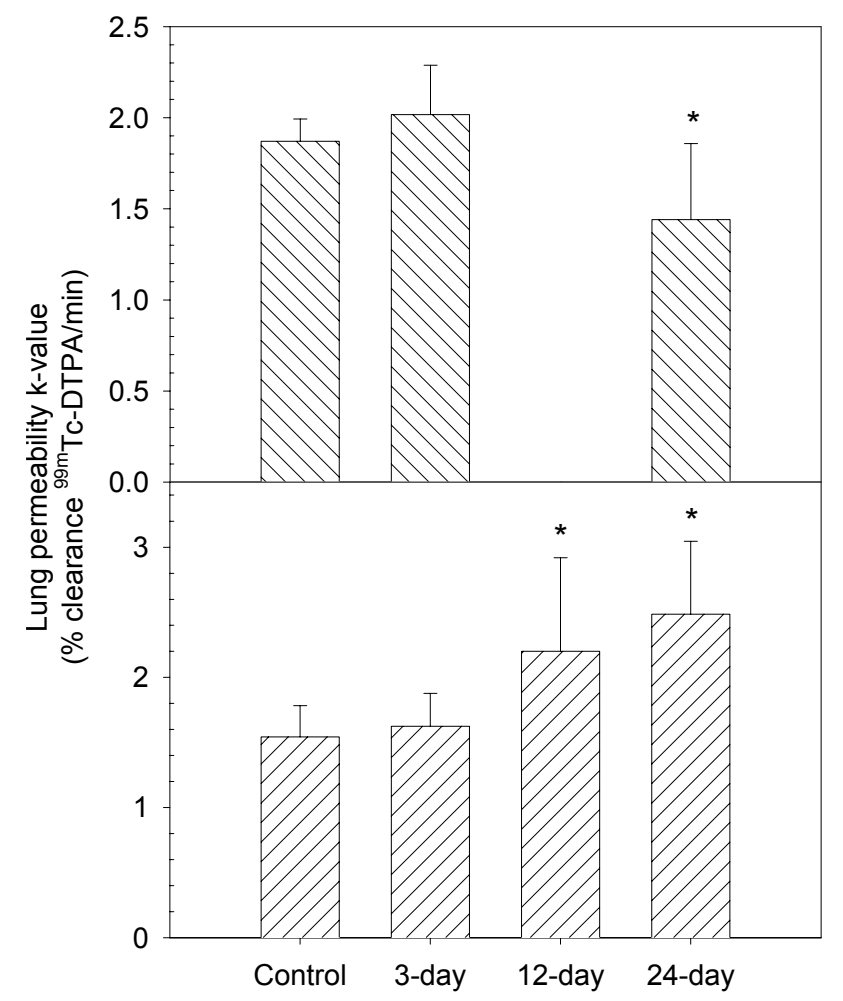

Figure 22. Doped distillate oil ash: lung permeabilities for $\mathrm{ZnO}$ aerosol (upper) and $\mathrm{ZnSO}_{4}$ aerosol (lower) for various exposure periods (1 hour per day, $\left.\sim 1000 \mu \mathrm{g} / \mathrm{m}^{3}\right)$.

made filter system was capable of collecting particles larger than $0.5 \mu \mathrm{m}$ at $99 \%$ efficiency. The particles were collected on the surface of the filter. After several hours of running one type of experimental condition, the collected particles were removed and stored in a desiccated container until further use. Equilibrium calculations suggest that the particles collected would consist of $\mathrm{ZnO}$ without sulfur present, and of $\mathrm{ZnSO}_{4}$ with sulfur present (Gordon and McBride, 1994).

Figure 21 shows the PSD's sampled from the furnace for particles from the $\mathrm{Zn}$ and $\mathrm{Zn}+\mathrm{S}$ doped runs. There is one nucleation mode between $0.1 \mu \mathrm{m}$ and $1 \mu \mathrm{m}$, indicating that vaporization has occurred. It is unlikely that re-suspension of collected ash particles allowed this ultrafine particle size distribution to be preserved for inhalation. Future work will employ in-line exposure to ultrafines without particle collection and re-suspension.

Figure 22 presents the biological response to inhalation of these re-suspended particles. It displays results of the lung permeability k-value of mice exposed to re-suspended zinc oxide $(\mathrm{ZnO})$ and zinc sulfate $\left(\mathrm{ZnSO}_{4}\right)$ ash particulate at various exposure time intervals, respectively. 
Even though both of these ash particles contained zinc, the physiological responses were quite different. In the case of $\mathrm{ZnO}$ particles, the k-value of the 3-day exposure mice set increased by a small amount but not statistically significant. The 24-day exposure mice set exhibited a significant decrease in lung permeability. The upper panel value in Fig 22 for the 12 day exposure is missing because of the expiration of experimental subjects while surgery was being performed.

The sulfated zinc particles, however, showed a different result on the lower panel of Fig 22. Any mice set exposed to these particles displayed an increase in lung permeability. A statistically significant change occurred for mice that were exposed for 12 days or more. Furthermore, the lung permeability increased as the exposure time, number of exposure days, increased. An increase in lung permeability can possibly pose a greater risk of allowing toxicants to come into contact with other organs. These data, with sulfur present, are consistent with the coal plus MSS data on Fig 1.

Mice that were exposed to both $\mathrm{ZnO}$ and $\mathrm{ZnSO}_{4}$ particles also had an obvious physical appearance that was different then control mice. The nasal septum and paws were bright red; the nasal septum redness was also observed with mice that were exposed to re-suspended coal/RDF ash particles. In addition to the outside physical appearance, other observations that were very obvious to observed was the increase in difficulty capturing pulmonary functions, the brownish lung color (some exposed mice had lung with patchy white spots) in instead of the healthy pink color of the lung and hypersensitivity to bleeding. From transmission electron microscopy, it was observed that indeed a change had occurred to mice that were exposed to zinc oxide particles. Cells in the alveolar region displayed an obvious increase in lamellar bodies and connective tissue, which would confirm the observed decrease in lung permeability. Therefore, these (essentially pure) $\mathrm{ZnO}$ particles cannot be considered "benign", even though they may be so defined here from a lung permeability point of view. Sulfur addition had a very great effect on the cell count profile of the BALF. Whereas, the cell count decreased over time with the $\mathrm{Zn}$ only case, it actually significantly increased for the $\mathrm{Zn}$ plus sulfur case. There are possible biological reasons for this (Fernandez, 2002), but from an health effects engineering point of the important conclusion is that particle speciation is critical, as was apparent also from the lung permeability data (Fig 22).

4.3.3 Health effects engineering to diminish lung injury from inhaled particles. Figures 23 and 24 show the effects of kaolinite sorbent addition to the total PSD (Fig 23) and the elemental PSD (Fig 24). Sorbent was added above the dewpoint of the zinc vapor. Using the method of aerosol fractionation (Gale and Wendt, 2002), 30\% of the Zn was reactively captured by the sorbent in the absence of sulfur and $40 \%$ was captured with sulfur present. Particles in the cyclone catch (nominally $>\sim 2 \mu \mathrm{m}$ ) can be assumed to contain only the sequestered zinc, and these were the particles for which their inhalation health effects were examined. Figure 25 shows that for both sorption cases in the presence and absence of sulfur, the approximate $1 / d_{p}$ dependencies of $\mathrm{Zn}$ concentration to particle size, in the larger particle size range, suggest external surface or pore diffusion controlled reaction of the $\mathrm{Zn}$ on the kaolinite (in contrast to film diffusion controlled physical condensation). These larger particles containing sequestered $\mathrm{Zn}$ on kaolinite were re-suspended and applied to the mice in the IN-TOX mouse chamber. Lung permeability results are shown on Fig 26, and show the previously observed "relatively 


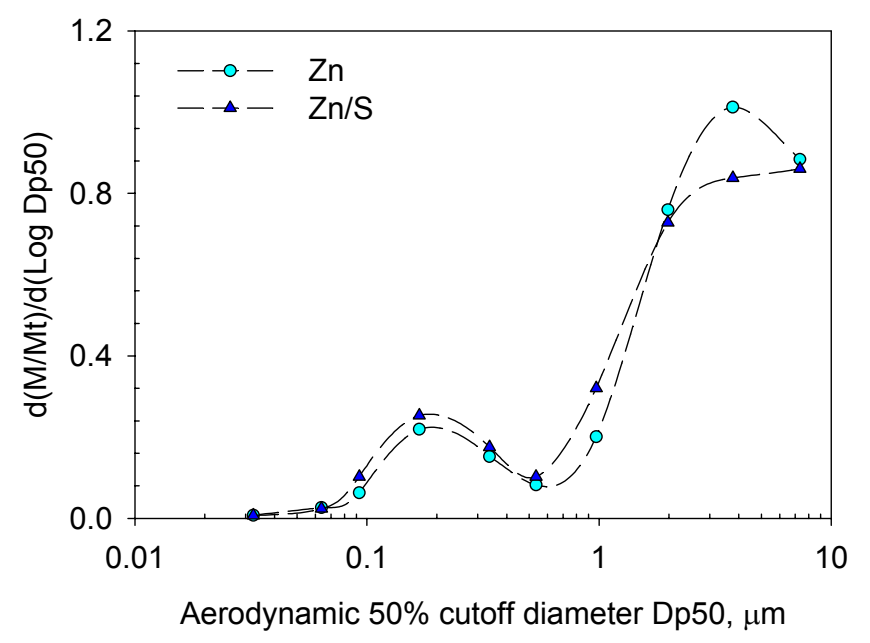

Figure 23. Particle PSD's with kaolinite sorbent added

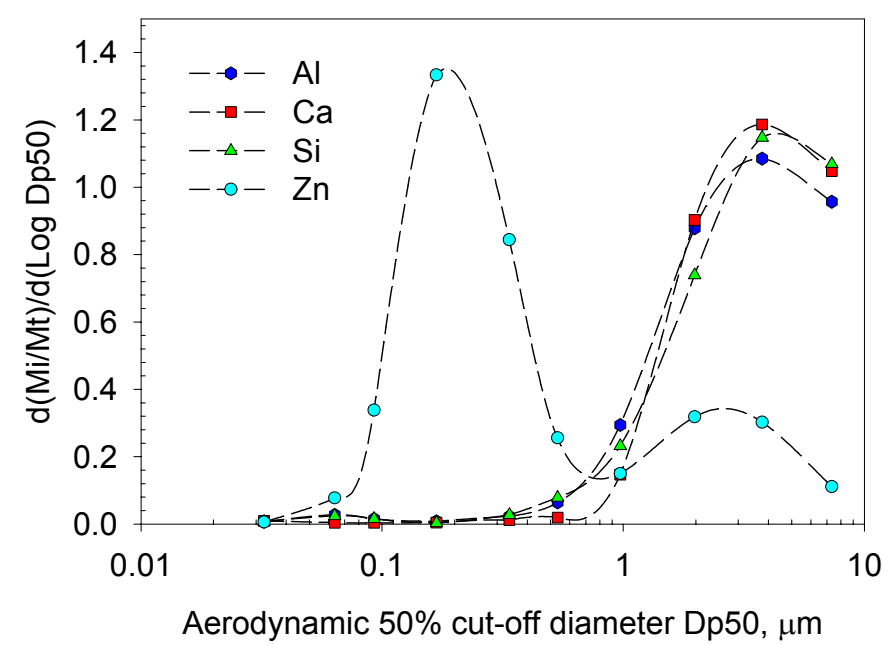

Figure 24. Elemental PSD of sampled ash with kaolinite sorbent injected into postflame. Area under curve yields fraction of element found within the limiting particle size range.

benign" behavior over time, similar to coal ash alone, and to other particulates, which did not cause a permeability, increase. Clearly, the health effects of increased permeability, shown on the lower panel of Fig 22, have been engineered out by sequestering the zinc by kaolinite powder. This suggests that sorbent addition to the post flame region of a flame of coal and MSS might also engineer out the potentially bad health effects observed there. 


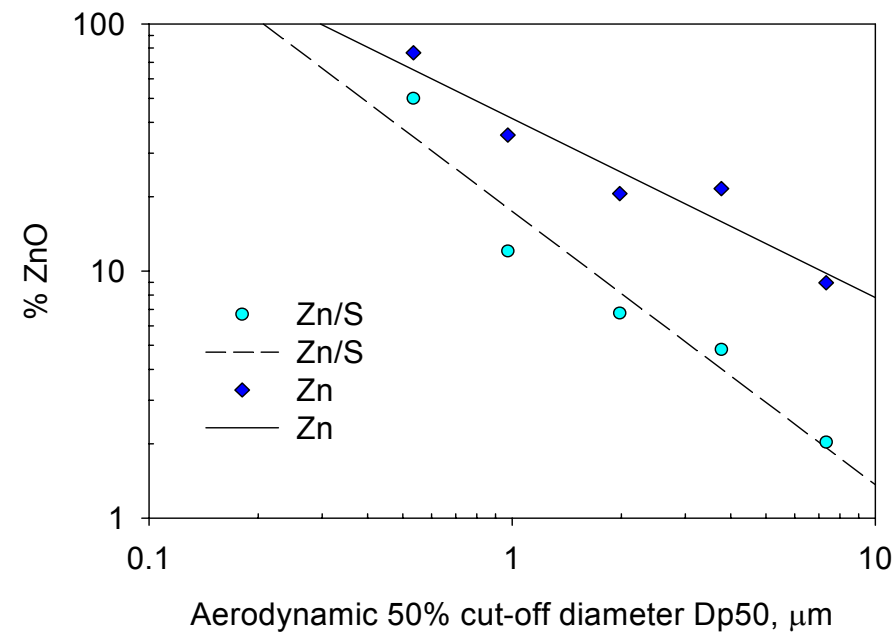

Figure 25. Composition/particle size dependence for large zinc containing particles after sorbent injection.

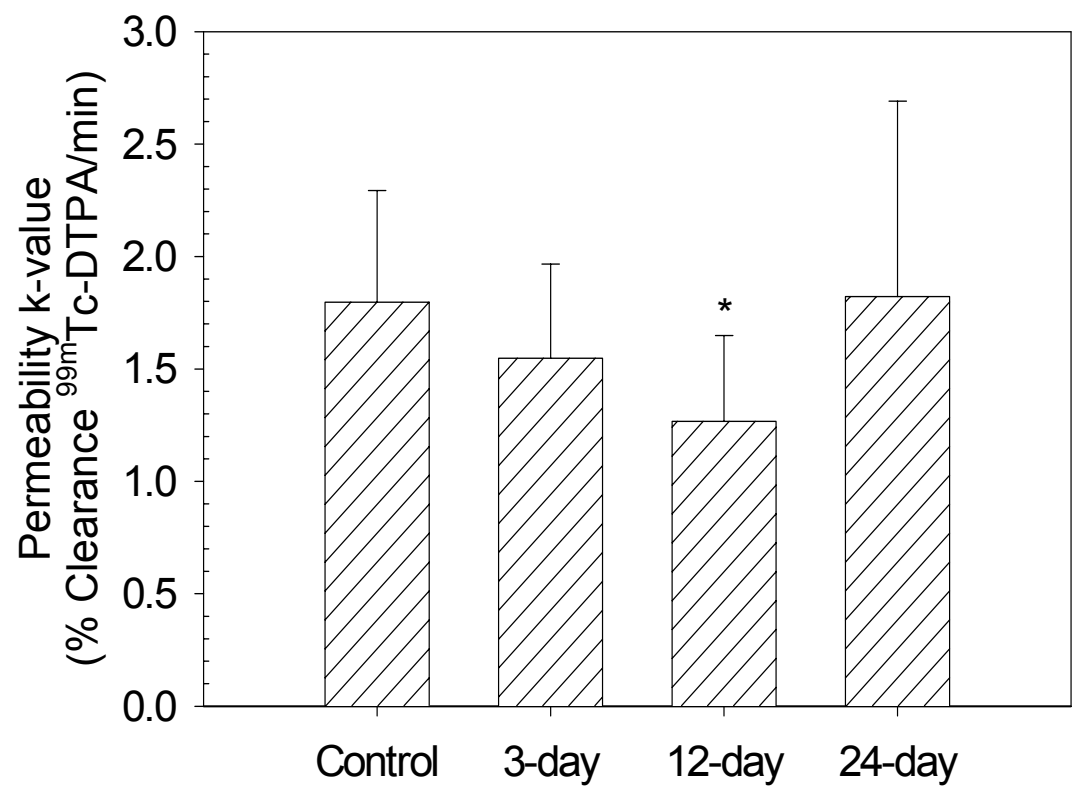

Figure 26: Lung permeabilities for larger sized inhaled particles. The long term increase of lung permeability (see Fig 5) due to inhaled ash particles when both zinc and sulfur are present in the combustor has been engineered out of the process by using a sorbent. 


\subsection{CONCLUSIONS}

Experiments were performed to examine the partitioning of four trace elements (As, Se, $\mathrm{Zn}$, and $\mathrm{Sb}$ ) during the combustion of MSS under two conditions: combustion with natural gas assist and co-fired on a 50-50 basis (based on heating value) with an Ohio blend coal. MSS combustion generates substantial bulk fly ash. However, the overall effect of including MSS in combustion does not appreciably increase or decrease the vapor-phase or submicron phase trace element mass loading. The vapor-to-solid phase partitioning of zinc does not appear to be transport process controlled under either combustion condition. By contrast, the vapor-to-solid phase partitioning of arsenic, selenium, and antimony is controlled by surface reaction with active surface sites during MSS combustion with either gas or coal. With gas assist, these oxy-anions appear to react with both calcium and iron surface sites. During co-combustion with a high sulfur $\left(3.5 \mathrm{wt} \%\right.$ as $\mathrm{SO}_{2}$ ) Ohio coal, these oxy-anions appear to react with calcium surface sites.

The elemental composition and speciation of combustion generated particles is very important in determining the consequent health effects caused by their inhalation. The new field of Health Effects Engineering results from this observation, and is useful in identifying the effects of fuels and operating conditions on the health effects of the particles produced, and in devising combustion modifications to diminish potentially bad health effects.

Using increased lung permeability as a marker for incipient lung injury and also as a marker for subsequent transport of pollutants into the blood and to other organs, two types of behavior due to particles are observed. The first type of behavior manifests itself as an initial decrease of permeability (possibly caused by inflammation) followed by a recovery to initial values in 24 days. Most particles (ash from coal alone, ash from MSS alone, $\mathrm{Zn}$ without sulfur, sequestered $\mathrm{Zn}$ ) follow this behavior. The second type of behavior manifests itself by a significant continuous temporal increase in lung permeability, which is undesirable because it allows greater access of impurities into the bloodstream. The only cases in this study that followed this behavior were ash from coal (containing S) and MSS (containing Zn) burned together, and particles formed from $\mathrm{Zn}$ and sulfur additives in oil burned together. This suggests that the "bad actor" for the previously reported coal+MSS health effects is the combination of Zn plus sulfur, rather than $\mathrm{Zn}$ alone.

Health effects engineering can be employed to diminish the health risk caused by burning fuels containing both zinc and sulfur. Injection of a kaolinite sorbent downstream of the flame, but above the $\mathrm{Zn}$ dewpoint, can sequester the $\mathrm{Zn}$, and react it to form a new species that causes the first (relatively benign) type of lung permeability behavior, rather than the second (damaging) type of increased lung permeability behavior which is typical of incipient lung damage and cardiovascular injury. Future work should apply this concept to units burning coal and MSS, and perhaps also to other biomass mixtures and municipal waste incinerators. 


\section{REFERENCES}

Adamson, I. Y. R., Prieditis, H., and Vincent, R., Toxicology and Applied Pharmacology 157: 43-50(1999)

Adamson, I. Y. R., Prieditis, H., Hedgecock, C., and Vincent, R. Toxicology and Applied Pharmacology 166: 111-119(2000)

Amdur, M. O. and Chen, L. C., Environmental Health Perspectives 79: 147-150(1989).

Amdur, M. O., Sarofim, A. F., Neville, M., Quann, R. J., McCarthy, J. F., Elliott, J. F., Lam, H. F., Rogers, A. E., and Conner M. W. Environ. Sci. Technol. 20: 138-145(1986)

Cenni, R., Frandsen, F., Gerhardt, T., Spliethoff, H., and Hein, K. R. G. (1998). Waste Management(18), 433-444(1998)

Costa, D. L. and Dreher, K. L. Environ. Health Perspectives 105(5): 1053-1060(1997)

Crowley, S., Finkelman, R.“Toxic Substances from Coal Combustion -- A Comprehensive Assessment," Phase I Final Report, DOE Contract DE-AC22-95PC95101, September, 1997.

Davis, S.B., Gale, T.K., Wendt, J.O.L., and W. P. Linak Twenty-seventh (International) Symposium on Combustion, 27:1785-1791 (1998)

Dockery, D. W. et al., New England J. Med. 329, 1753-1759 (1993).

Fernandez, A. "On Inhalation Health Effects of Combustion Generated Particulates" Ph.D. Dissertation, Department of Chemical and Environmental Engineering, University of Arizona, Tucson, AZ 85721(2002)

Fernandez, A., Davis, S. B., Wendt, J. O. L., Cenni, R., Young, R. S., and Witten, M. L. Nature 409: 998. (2001).

Fernandez, A., Wendt, J.O.L, Cenni, R, Young, S.R., and Witten, M.L. The Science of the Total Environment, 287, 265-274(2002)

Gale, Thomas K., and Wendt, J.O.L. Combust.Flame 131, 299-307 (2002).

Ghio, A. J., Stonehuerner, J., Dailey, L. A., and Carter, J. D. Inhalation Toxicology, 11, 3749(1999)

Gordon, S. a. M., B. "Computer Program for Calculation of Complex Chemical Equilibrium Compositions and Applications, NASA reference publication 1311." (1994). 
Hall, J.E. "Treatment and use of sewage sludge in EC", in The Treatment and handling of wastes, Bradshaw, A.D., Southwood, R., and F. Warner (eds.), Chapman and Hall, London (1992)

Helble, J.J. and Sarofim, A.F. Combust. and Flame, 76:183-196 (1989)

Hillamo, R.E. and Kauppinen, E.I. Aerosol Sci Techol, 14:33-47(1991).

Lighty, J. S., Veranth, J. M. and Sarofim, A. F., J. Air Waste Manag. Assoc. 50, 1565-1618 (2000).

Linak, W.P. and T. W. Peterson, Aerosol Sci. Technol, 3:77-96 (1984).

Linak, W.P., Miller, C.A, and Wendt, J.O.L. J. Air Waste Manage. Assoc., 50, 1532-1544(2000)

Linak, W.P., Seames, W.S., Wendt, J.O.L., Ishinomori, T., and M. Shigehiro (2001), "On Trimodal Particle Size Distributions in Fly Ash from Pulverized Coal Combustion”, Proc. Combust. Institute 29 (2002), in press

Markowski, G.R. and Ensor, D.S. "A Procedure for Computing Particle size Dependent Efficiency for control devices from cascade impactor data", Proceeding of $70^{\text {th }}$ Annual Meeting of the Air Pollution Control Association, Toronto (1977)

McNallan, M.J., Yurek, G.J., and J.F. Elliott, Combust. Flame, 42:45-60(1981)

Moss, O. R. and Kenoyer, J. L.Use and Misuse: Operation Guide. Cascade Impactor. L. J. P. a. C. T. L. Akron, OH, American Industrial Hygiene Association: 23-42(1986)

Mulholland, J.A. and Sarofim, A.F. Environ Sci \& Tech, 25:268-274(1990)

Natusch, D.F.S., Wallace, J.F., and Evans, C.A. (1974), Science, 183:202-204.

Prahalad, A. K., Soukup J. M., Inmon, J., Willis, R., Ghio, A. J., Becker, S., and Gallagher, J. E. Toxicology and Applied Pharmacology, 158, 81-91(1999).

Reynolds, H. Y., Immunol., 111, 358-368.(1973)

Rodarte, J.R. and Rehder, K., pp131-144 in Bethesda, ed. Handbook of Physiology: The Respiratory System, Am Physiol Soc. (1986)

Sarofim, A.F., Howard, J.B., and Padia, A.S. Combust. Sci. and Technol., 16:187-204(1977).

Scheurer, W. (1999), Informal Correspondence.

Seames W.S. and Wendt, J.O.L., Proceedings Combust Inst, 28, pp 2305-2312 (2000). 
Seames, W.S. "The Partitioning of Trace Elements during Pulverized Coal Combustion", Ph.D. Dissertation, Department of Chemical and Environmental Engineering, University of Arizona(2000)

Seames, W.S. and J.O.L. Wendt, "The Partitioning of Selenium during Pulverized Coal Combustion", Combustion Institute Western States Regional Meeting, March 14, 2000, Golden, Co.

Seames, W.S. and Wendt, J.O.L. Fuel Proc. Tech., 63:170-196(2000)

Senior, C.L. and Flagan, R.C. (1982), Aerosol Sci. Tech., 1:371-383(1982).

Senior, C.L., Bool III, L.E., Huggins, F., Huffman, G.P., Shah, N., Wendt, J.O.L., Seames, W., Peterson, T., Shadman, F., Helble, J., Wornat, M., Sarofim, A., Olmez, I., Senior, C.L., Huggins, F., Huffman, G.P., Shah, N., Yap, N., Wendt, J.O.L., Seames, W., Ames, M.R., Sarofim, A., Swenson, S., Lighty, J.S., Kolker, A., Finkelman, R., Palmer, C.A., Mroczkowski, S.J., Helble, J., Mamani-Paco, R., Sterling, R., Dunham, G., and Miller, S. (2001), "Toxic Substances from Coal Combustion -- A Comprehensive Assessment," Final Report, DOE Contract DE-AC22-95PC95101, July 2001.

Smith, R.D. Prog. Energy and Combust. Sci., 6:53-119(1980).

Taylor, D.D. and Flagan, R.C., Aerosol Sci Tech, 1:103-117(1983).

Wall, T.F., Lowe, A., Wibberley, L.J., and Stewart, I.M., Prog Energy Combust Sci, 5:129(1979).

Werther, J. and Ogada, T. Prog. Energy Combust. Sci, 25:55-116(1999). 